\title{
Oligomerization of NLR immune receptor RPP7 triggered by atypical resistance protein RPW8/HR as ligand
}

Lei Li,' Anette Habring,' Kai Wang,'² and Detlef Weigel',*

IDepartment of Molecular Biology, Max Planck Institute for Developmental Biology, 72076 Tübingen, Germany 2Department of Cell Biology, Max Planck Institute for Developmental Biology, 72076 Tübingen, Germany

*Correspondence: E-mail weigel@weigelworld.org

In certain plant hybrids, autoimmunity is triggered by immune components that interact in the absence of a pathogen trigger. Often, NLR immune receptors are involved, with a particularly interesting case in Arabidopsis thaliana involving variants of the NLR RPP7 as well as variants of RPW8/HR proteins, which are homologs of animal MLKL and fungal HELL domain proteins. We demonstrate that HR4Fei-0 but not the closely related HR4Col-0 protein directly disrupts intramolecular association of RPP7bLerik 1-3, which in turn initiates P-loop dependent NLR signaling. In agreement, RPP7bLerikl-3 forms a higher-order complex only in the presence of HR4Fei-0 but not HR4Col-0. In addition, we find that HR4Fei0 on its own can form detergent-resistant oligomers suggestive of amyloid-like aggregates, which in turn can directly kill cells in an RPP7bLerikl-3-independent manner. Our work provides in vivo biochemical evidence for a plant resistosome complex and the mechanisms by which RPW8/HR proteins trigger cell death.

\section{INTRODUCTION}

Multicellular organisms and their microbial pathogens are engaged in a perpetual evolutionary race, and the genes hosts use to stay ahead of their enemies generally belong to the most variable and diverse gene families. This is the case for the dominant type of intracellular plant immune receptors, nucleotide-binding and leucine rich repeat domain (NLR) proteins, which are closely related to animal NOD/CARD proteins (Jones et al., 20I6; Maekawa et al., 20I la). Plant NLRs can be classified into CC-NLRs (CNLs) and TIR-NLRs (TNLs) based on their N-termini, which include either coiled-coil (CC) or Toll/interleukin-I receptor (TIR) domains (Qi and Innes, 20I3; Zhang et al., 2017a). 

aCC-BY 4.0 International license.

Plant NLRs directly or indirectly recognize non-self molecules mainly, though not exclusively, through their C-terminal LRR domain (Ade et al., 2007; Dodds et al., 2006; El Kasmi et al., 2017; Krasileva et al., 20 I0; Rairdan et al., 2008; Steinbrenner et al., 20I5). The detection of non-self molecules leads to conformational changes, followed by the release of intramolecular interactions, which in turn expose the N-terminal CC or TIR domains for participation in downstream signaling (Bernoux et al., 20I I; Casey et al., 2016; Cesari et al., 2016; Maekawa et al., 20I lb; Wang et al., 20l9a, 2019b).

The importance of self-associations for the function of plant NLR proteins has been highlighted in several studies. For example, the TNLs SNCI, N and RPPI can all form oligomers, or at least dimers, either before or after activation (Mestre and Baulcombe, 2006; Schreiber et al., 2016; Xu et al., 20I4). Two different interfaces in the TIR domains of SNCI and RPPI can support self-association, potentially enabling TNLs to assemble higherorder complexes (Zhang et al., 2017b). Similarly, several CNL full-length receptors, such as MLA, Sr33, Sr50, RPS5 and Rx, can self-associate (Ade et al., 2007; Casey et al., 20I6; Cesari et al., 2016; Maekawa et al., 20I Ib; Moffett et al., 2002). In addition, structural and phenotypic analyses have indicated that an extended CC fragment of $\mathrm{Sr} 33$ can dimerize and activate signaling, while a shorter fragment cannot (Casey et al., 2016). Cryo-EM analysis of the CNL ZARI has revealed how uridylation of the ZARI ligand PBL2 induces ZARI oligomerization in vitro. In its resting state, ADP-bound ZARI is complexed with adaptor protein RKSI in a conformation that buries the oligomerization interfaces. Upon interaction of RKSI with uridylated effector PBL2, ADP release allows ATP/dATP to enter the binding pocket, triggering a ZARI conformational change that exposes the oligomerization interfaces, which finally leads to formation of a wheel-like pentameric complex. A key event during oligomerization is the rearrangement of the CC domains, which end up forming a funnel-shaped structure that has been speculated to directly disrupt the plasma membrane (Dangl and Jones, 2019; Wang et al., 20I9a, 2019b).

Some NLRs acts as sensors that positively regulate helper NLRs, although it is unknown whether these helper and sensor NLRs reside in a single complex. For example, tobacco NRGI, A. thaliana ADRI, and Solanaceae NRCs mediate signaling activated by multiple plant sensor NLRs (Bonardi et al., 20 I I; Castel et al., 20I8; Collier et al., 20I I; Peart et al., 2005; Wu et al., 2017, 20I8b), likely interacting only indirectly with TNLs (Qi et al., 2018). Notably, these helper NLRs belong to a subclass of CNLs whose CC domains are similar to parts of the non-NLR RPW8/HR immune proteins (and therefore referred to as $C_{R}$ domains) (Collier et al., $20 \mathrm{II})$. Similar to many NLR genes, the $C_{R} C_{R}$-only $R P W 8 / H R$ genes are located in a gene cluster, with extensive copy number and sequence variation between wild strains (Barragan et al., 2019; Jorgensen and Emerson, 2008; Orgil et al., 2007; Xiao et al., 2004). However, different from typical NLRs, which function primarily in racespecific resistance, $R P W 8 / H R$ genes seem to be mostly involved in broad spectrum resistance (Ma et al., 20I4; Wang et al., 2007; Xiao et al., 200I). The $C C_{R}$ domain is predicted to be structurally related to portions of animal mixed-lineage kinase domain-like (MLKL) and fungal HeLo and HeLo-like (HELL) domains, which share structures characterized by four-helix bundles (Bentham et al., 20I8; Jubic et al., 2019). Similar to the fungal HeLo domain protein Het-S, RPW8/HR is predicted to have an N-terminal transmembrane domain, a central $C_{R} / M L K L / H E L L$ 

aCC-BY 4.0 International license.

Li et al.

RPW8/HR proteins and plant NLR oligomerization

domain, as well as C-terminal repeats (Barragan et al., 2019). The $\mathrm{N}$-terminal domain of Het-S can insert into membranes, thereby forming a pore and inducing cell death, while the regulatory C-terminal $2 \mathrm{I}$-amino acid repeats constitute a prion-forming domain (PFD) that can regulate Het-S activity by adopting an amyloidal structure (Daskalov et al., 2016; Greenwald et al., 2010; Seuring et al., 2012).

There has been no prior evidence that RPW8/HR proteins function as helpers to sensor NLRs, although genetic evidence has linked different alleles of the CNL locus RPP7 to different alleles at the RPW8/HR locus. When wild strains of $A$. thaliana are crossed, the $F_{1}$ hybrid progeny of specific crosses can express autoimmunity indicative of activated NLR signaling in the absence of a pathogen trigger. In at least three such cases, the causal factors are a specific allele of RPP7 from one parent and a specific allele of RPW8/HR from another parent (Barragan et al., 2019; Chae et al., 2014). Here, we demonstrate that RPW8/HR proteins can directly interact in an allele-specific manner with RPP7 proteins. The interaction disrupts RPP7 intramolecular association, which in turn leads to assembly of a higher-order RPP7 complex and autoimmune signaling; these findings provide biochemical evidence for the in vivo formation of a plant resistosome complex, which before only has been observed in vitro (Wang et al., 2019a, 2019b). In addition, we demonstrate that RPW8/HR proteins can kill cells on their own by forming potentially amyloid-like aggregates. Our study highlights how two different arms of plant immunity converge in form of the atypical resistance protein RPW8/HR and the conventional immune receptor RPP7.

\section{RESULTS}

\section{Specificity in genetic interaction between RPP7 and RPW8/HR}

Our previous studies identified RPW8.I from KZIO and HR4 from Fei-0 as causal for hybrid necrosis when combined with specific alleles at the RPP7 locus from Mrk-0 and LerikI-3, respectively (Barragan et al., 2019). We demonstrated causality of RPP7Mrk-0 using transformation of a genomic RPP7Mrk-0-3xFLAG construct into the KZIO accession and with rpp7 frameshift mutations in Mrk-0, and we confirmed that RPP7Mrk-0 and RPW8.I KZI0 are sufficient for inducing a strong hypersensitive response in a heterologous system, Nicotiana benthamiana (Figure SIA, SIB, SIC).

The RPP7 genomic locus can be complex (Guo et al., 20I I), but this is not the case in Mrk-0, which has only a single RPP7 paralog (Figure SID). We found a more interesting situation in LerikI-3, which similar to the reference accession Col-0 contains three paralogs, which we named RPP7 (the ortholog of the functionally defined RPP7 cluster member in Col-0 (Eulgem et al., 2007)), RPP7a and RPP7b (Figure SID). Only RPP7b but not RPP7 and RPP7a triggered a confluent hypersensitive response in combination with HR4Fei-0 in N. benthamiana (Figure IA), even though RPP7b-Myc protein accumulated to much lower levels than RPP7a-Myc (Figure SIE). To further confirm RPP7b Lerikl-3 (hereafter referred to as RPP7b) as causal, we introduced each of the three RPP7 paralogs, driven by the same RPP7b promoter, into the incompatible accession Fei- 0 and the neutral Col-0 background. All 
bioRxiv preprint doi: https://doi.org/10.1101/682807; this version posted June 25,2019 . The copyright holder for this preprint (which was not certified by peer review) is the author/funder, who has granted bioRxiv a license to display the preprint in perpetuity. It is made available under aCC-BY 4.0 International license.

Li et al.

RPW8/HR proteins and plant NLR oligomerization

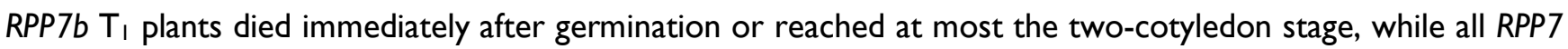

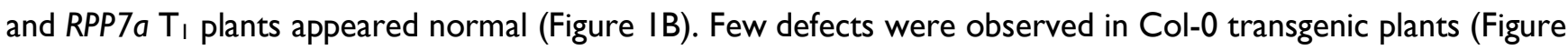
SIF), with occasional defects such as curled leaves that are also seen in other NLR mis-expressers (Holt et al., 2005). Finally, we combined RPP7b-3×FLAG and HR4Fei-0-3 $\times$ HA under control of their native promoters in one construct. All three independent stable $\mathrm{T}_{2}$ lines in Col-0 recapitulated the LerikI-3 $\times$ Fei- 0 F 2 hybrid necrosis phenotype at $23^{\circ} \mathrm{C}$ (Figure IC and SIG). Together, these results demonstrated that a specific member of the RPP7 cluster in LerikI-3, RPP7b, is the causal gene for hybrid necrosis in the LerikI-3 $\times$ Fei- 0 cross. The three RPP7 paralogs in LerikI-3 represent three major clades of RPP7-like genes in A. thaliana, providing a natural platform for understanding specificity in the genetic interaction between HR4Fei-0 and RPP7b.
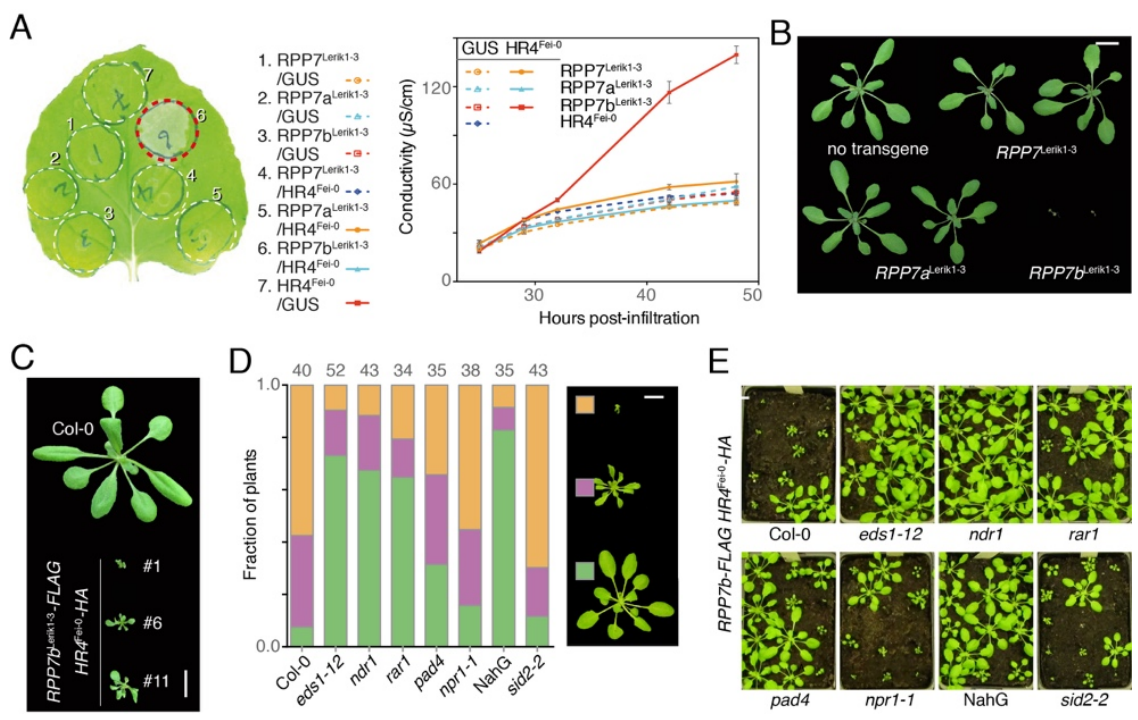

Figure I. Genetics of HR4Fei-0/RPP7b-induced hybrid necrosis

(A) Left, hypersensitive response (indicated by a red circle) induced by co-expression of RPP7b ${ }^{\text {Lerikl-3 }}$ with HR4 $4^{\text {Fei-0 }}$ in $\mathrm{N}^{\text {. }}$ benthamiana, four days after Agrobacterium infiltration. Experiments were performed at least three times. Right, lon leakage measurements of plants shown on left. Values are means \pm SEM $(n=3)$. Each sample contains eight leaf discs from different plants, and experiments were performed at least twice. (B) Recapitulation of LerikI-3 $\times$ Fei- 0 hybrid necrosis with genomic $R P P 7 b^{\text {Lerikl-3 }}$ construct in four-week-old $\mathrm{T}_{1}$ transgenic Fei- 0 plants, grown at $23^{\circ} \mathrm{C}$. RPP7 genes were expressed under the control of the RPP7b promoter. Size bar corresponds to I cm. (C) Recapitulation of LerikI-3 $\times$ Fei-0 hybrid phenotype by co-expression of $R P P 7 b^{\text {Lerikl-3 }}$ and $H R 4^{\text {Fei-0 }}$ under control of their native promoters in Col-0 background. Three independent $\mathrm{T}_{2}$ transgenic lines grown at $23^{\circ} \mathrm{C}$ are shown. Size bar corresponds to $1 \mathrm{~cm}$. (D) Distribution of different phenotypes in $A$. thaliana $\mathrm{T}$, plants with RPP7b::RPP7b-FLAG and HR4::HR4 $4^{\mathrm{Fe}-0}-\mathrm{HA}$ transgenes in different backgrounds, grown at $23^{\circ} \mathrm{C}$. The numbers above indicate the total $\mathrm{T}_{\text {I }}$ plants scored according to the scale shown on the right. Size bar corresponds to I $\mathrm{cm}$.

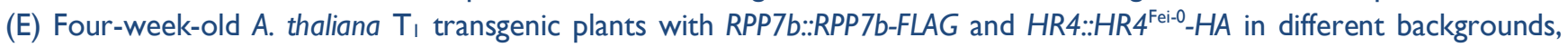
grown at $23^{\circ} \mathrm{C}$. Size bar corresponds to $1 \mathrm{~cm}$.

\section{Genetic requirements for HR4Fei-0/RPP7b-induced plant autoimmunity}

Hybrid necrosis cases such as HR4Fei-0/RPP7b present an opportunity to investigate NLR signaling without the complication of effector-triggered modifications of NLR ligands. To determine whether HR4Fei-0/RPP7b provides an appropriate model for pathogen-dependent signaling by NLRs, we sought to determine whether the genetic interaction between RPP7b and HR4Fei-0 requires known downstream components of canonical NLR signaling. EDSI and PAD4 typically act as positive regulators of TNL pathways, NDRI mainly plays a positive role 
downstream of CNLs (Aarts et al., 1998; Wagner et al., 20I3), and RARI and SGTIb control the stability of NLR proteins (Hubert et al., 2009; Zhang et al., 20I0). Finally, NPRI mediates the effects of the important signaling molecule salicylic acid (SA) (Cao et al., 1997; Ding et al., 2018). SA itself can be manipulated with mutations in the SA biosynthesis gene SID2, and to an even greater extent by expressing the bacterial enzyme NahG, which catabolizes SA (Nawrath and Métraux, 1999; Wildermuth et al., 200I). All of these components but NDRI are essential for RPW8.2Ms-0 signaling during powdery mildew resistance (with SID2 not having been tested) (Xiao et al., 2005), while RPP7Col-0 signaling during downy mildew resistance appears to rely on multiple, redundant pathways, such that ndrl mutation or a NahG transgene on their own have only weak effects on RPP7Col-0_ mediated resistance (McDowell et al., 2000).

We transformed the RPP7b::RPP7b-3×FLAG / HR4::HR4Fei-0-3×HA construct into the aforementioned mutants. Necrosis was effectively suppressed not only by eds I, but also by $n d r l$, which sets autoimmunity triggered by HR4Fei-0/RPP7bLerikl-3 apart from RPW8.2Ms-0_ and RPP7Col-0-dependent resistance to powdery and downy mildew, respectively (Figure ID). More similar to RPW8.2Ms-0 (Xiao et al., 2005), but different from what has been reported for RPP7Col-0 (McDowell et al., 2000), NahG strongly attenuated HR4Fei-0/RPP7bLerikl-3_induced necrosis, while $n p r l$ and sid2 did not (Figure IE). The requirement for multiple disease resistance signaling components is consistent with HR4Fei-0/RPP7b hybrid necrosis mimicking conventional, pathogen-triggered signaling. At the same time, the differences between pathogen-triggered signaling initiated by RPW8.2Ms-0 and RPP7Col-0 as well as pathogen-independent signaling by HR4Fei-0/RPP7blerikl-3 suggest that not all RPW8/HR and RPP7 proteins act through the same pathways.

\section{RPP7b oligomerization induced by association with HR4Fei-0}

Certain conventional NLRs work as heteromeric pairs, through interacting N-terminal domains (Césari et al., 2014; Tran et al., 2017; Williams et al., 20I4). RPP7 proteins are canonical CNLs, while RPW8/HR proteins are non-NLR, $C_{R}$-only proteins. Co-immunoprecipitation (co-IP) indicated that HR4Fei-0 and RPP7b associate in A. thaliana cells (Figure 2A), and truncation analysis revealed that the CC and LRR domains of RPP7b are mainly responsible for interaction with HR4Fei-0 (Figure S2A). The CC and LRR domains of RPP7b can bind HR4Fei-0 directly, as demonstrated with in vitro pull-down assays (Figure 2B).

We further investigated the specificity of the physical interaction between RPP7b and HR4Fei-0 using $A$.

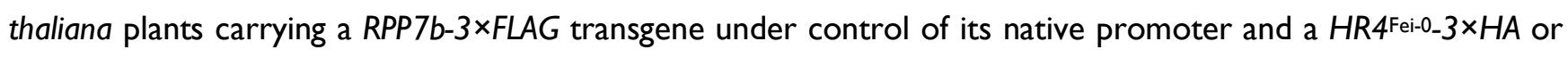
$H R 4$ Col-0-3 $\times H A$ transgene under control of an estradiol-inducible promoter. Only the HR4Fei-0-3 $\times H A$ but not the HR4Col-0-3 $\times$ HA plants produced necrosis after estradiol treatment (Figure S2B). In co-IPs, we consistently observed that RPP7b associated with HR4Fei-0 more strongly than with HR4Col-0 (Figure 2C), consistent with HR4Fei-0/RPP7b interaction being a prerequisite for activation of immune signaling.

To investigate whether HR4Fei-0 and RPP7b form stable complexes in vivo, and to determine the size of such complexes, we turned to Blue Native polyacrylamide gel electrophoresis (BN-PAGE) of material extracted from transgenic $A$. thaliana plants. In the absence of HR4Fei-0, we detected an RPP7b complex of about 300 kD 
bioRxiv preprint doi: https://doi.org/10.1101/682807; this version posted June 25,2019 . The copyright holder for this preprint (which was not certified by peer review) is the author/funder, who has granted bioRxiv a license to display the preprint in perpetuity. It is made available under aCC-BY 4.0 International license.

Li et al.

RPW8/HR proteins and plant NLR oligomerization

(Figure 2D) but not a RPP7b monomer, implying that RPP7b exists in the resting state in a homomeric complex (or in a heteromeric complex with another protein). RPP7b shifted to a larger complex of about $900 \mathrm{kD}$ in the presence of HR4Fei-0 but not HR4Col-0 (Figure 2D). Analysis of complexes in a second dimension of SDS-PAGE further verified that HR4Fei-0 can promote higher-order oligomerization of RPP7b, with HR4Fei-0 being present in high-molecular-mass complexes (Figure 2E). Taken together, these results demonstrate that signaling by the plant NLR RPP7b requires formation of a higher-order oligomeric complex. This observation is consistent with cryoEM studies of complexes of plant NLR ZARI and animal NLR NLRC4 (Hu et al., 20I5; Wang et al., 20I9b; Zhang et al., 20I5).

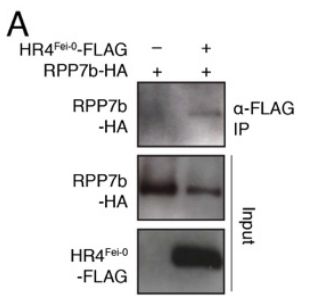

B

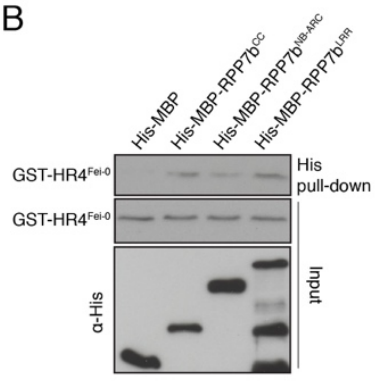

$E$

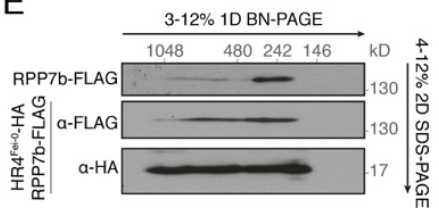

C

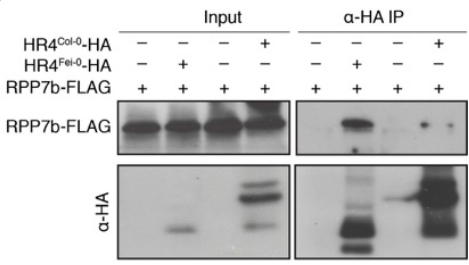

$\mathrm{D}$

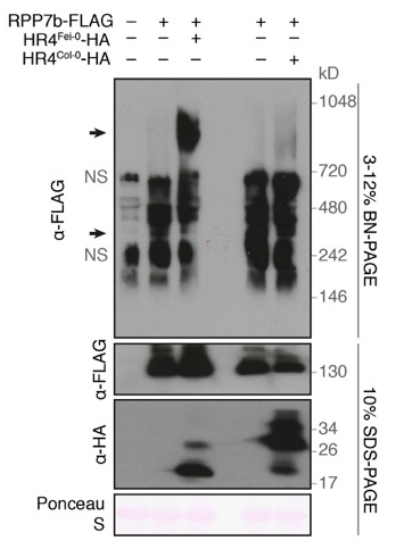

Figure 2. HR4Fei-0 associates with RPP7b and induces oligomerization of RPP7b

(A) HR4 $4^{\text {Fei-0 }}$ interacts with RPP7b in vivo, as shown by co-IP from A. thaliana protoplasts. (B) HR4 ${ }^{\text {Fei- } 0}$ interacts with RPP7b in vitro, as shown by pull-down assays with proteins purified from $E$. coli. (C) HR4 ${ }^{\text {Fei-0 }}$ interacts with RPP7b in vivo, as shown by co-IP from transgenic $A$. thaliana plants. Expression of RPP7b::RPP7b-FLAG and HR4 $4^{\text {Fei-0. }}$-HA or HR4 ${ }^{\text {Col-0 }}-\mathrm{HA}$ was induced by $\beta$-estradiol. (D) HR4 ${ }^{\text {Fei-0 }}$ induces oligomerization of RPP7b, as shown by BN-PAGE and SDS-PAGE. Arrows point to RPP7b complexes. NS indicates nonspecific bands. (E) Evidence for HR4 $4^{\text {Fei-0 }}$ and RPP7b residing in the same complex, as shown with second-dimension SDS-PAGE using lanes 2 and 3 of BN-PAGE in (D). Experiments were performed at least three times.

\section{Requirement of P-loop function for HR4Fei-0-induced RPP7b oligomerization}

An attractive model of plant NLR function has NLRs existing in an equilibrium between an active ATP-bound and an inactive ADP-bound state (Bernoux et al., 2016). The balance between the active and inactive state in turn is thought to be regulated by ligands that affect intramolecular interactions between different NLR domains (Ade et al., 2007; Bernoux et al., 2016; Moffett et al., 2002; Schreiber et al., 2016), consistent with the structures of inactive and active ZARI forms (Wang et al., 2019a, 2019b). 
bioRxiv preprint doi: https://doi.org/10.1101/682807; this version posted June 25, 2019. The copyright holder for this preprint (which was not certified by peer review) is the author/funder, who has granted bioRxiv a license to display the preprint in perpetuity. It is made available under aCC-BY 4.0 International license.

To investigate how the association with HR4Fei-0 might affect intra- and/or intermolecular interactions between different RPP7b domains, we carried out co-IP assays with material from $A$. thaliana protoplasts that coexpressed combinations of CC, NB-ARC or LRR domains of RPP7b. The LRR domain interacted strongly with CC and NB-ARC domains, and the NB-ARC domain interacted weakly with the CC domain (Figure 3A), indicating that all RPP7b domains contribute to intramolecular association. Furthermore, both the CC and LRR domains can self-associate (Figure 3A), suggestive of dimerization through homophilic intermolecular interactions.

A

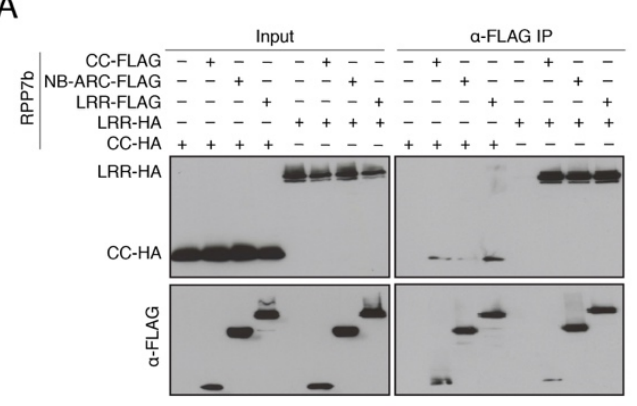

C

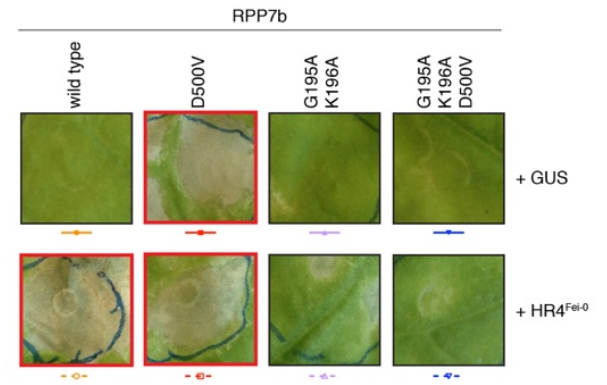

B
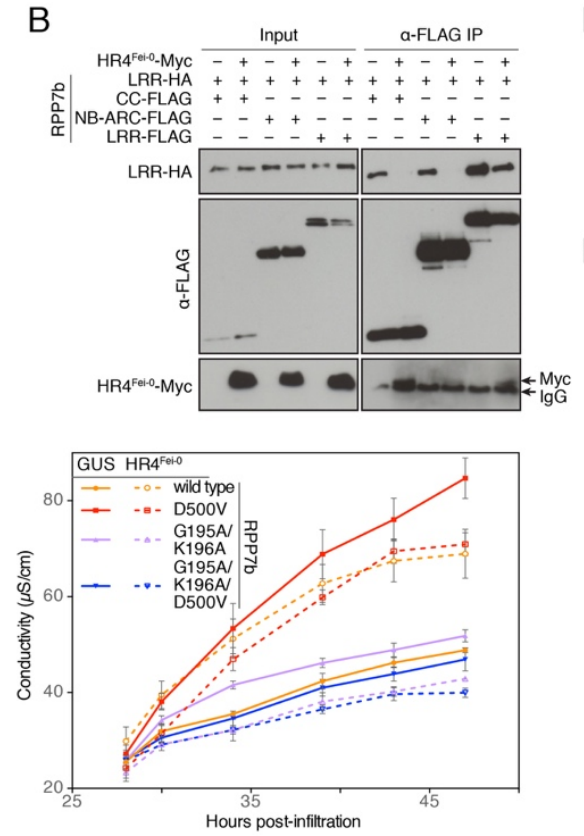

D

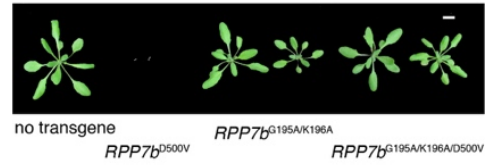

E

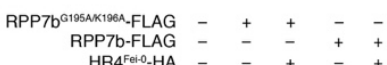

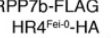

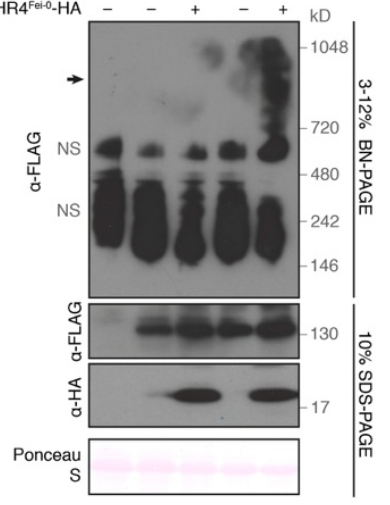

Figure 3. HR4Fei-0 induces oligomerization of RPP7b in a P-loop dependent manner

(A) Interaction between RPP7b domains, as shown by co-IP from A. thaliana protoplasts. (B) HR4 ${ }^{\text {Fei- } 0}$ weakens interactions between RPP7b domains, as shown by co-IP from A. thaliana protoplasts. (C) Analysis of RPP7b variants with P-loop and MHD motif mutations in N. benthamiana, seven days after Agrobacterium infiltration. RPP7b variants, all expressed under the control of the RPP7b promoter, were co-expressed with HR ${ }^{\text {Fei- }}$. Left, images of leaves; hypersensitive response is indicated by red frames. Experiments were performed at least three times. Right, ion leakage measurements of plants shown on left. Values are means $\pm \operatorname{SEM}(n=3)$. Each sample contains eight leaf discs from different plants, and experiments were performed at least twice. (D) Analysis of P-loop and MHD motif mutants in A. thaliana. Four-week-old $T_{1}$ transgenic plants with RPP7b variants expressed from RPP7b promoter in Fei-0 background, grown at $23^{\circ} \mathrm{C}$. Size bar corresponds to I cm. (E) HR4 $4^{\text {Eei-O }}$ induces oligomerization of RPP7b in a P-loop dependent manner, as shown by BN-PAGE and SDS-PAGE. Arrow points to RPP7b high-molecular weight complexes. NS indicates nonspecific bands.

Since HR4Fei-0 interacts directly with RPP7b and promotes formation of a higher-order complex, we next asked whether HR4Fei-0 affects intra- and/or intermolecular RPP7b interactions. We transiently expressed RPP7b domains in the absence or presence of HR4Fei-0 in A. thaliana protoplasts and performed co-IPs. We observed that HR4Fei-0 significantly weakened interactions between the LRR domain and either the CC or NB-ARC domain, whereas the homophilic interaction between LRR domains was unaffected by HR4Fei-0 (Figure 3B). In combination with the results from BN-PAGE, we conclude that HR4Fei-0 induces conformational changes of RPP7b that alter 

aCC-BY 4.0 International license.

Li et al.

RPW8/HR proteins and plant NLR oligomerization

the interaction between its different domains, resulting in RPP7b oligomerization as a prerequisite for downstream immune signaling.

To determine whether the inferred conformational changes of RPP7b depend on an active ATP-binding P-loop motif (Sukarta et al., 2016; Tameling et al., 2006; Williams et al., 20I I), we substituted the GMGGLGKT motif with GMGGLAAT. This mutation significantly attenuated RPP7b activity when co-expressed with HR4Fei-0 in N. benthamiana (Figure 3C). Conversely, changing the ADP-binding pocket motif MHD to MHV, known to render many NLRs constitutively active because it destabilizes the ADP-bound state (Sukarta et al., 2016; Tameling et al., 2006; Williams et al., 20II), conferred constitutive activity on RPP7bD500v in the absence of the HR4Fei-0 partner (Figure 3C). However, it could not override the inactivating effects of the P-loop mutation, neither in the presence or absence of HR4Fei-0 (Figure 3C). We confirmed that this was not due to insufficient protein accumulation (Figure S3A), and we also confirmed the effects of the different mutations and their combination by transforming RPP7b mutant variants into the Fei-0 background (Figure 3D).

We further analyzed the interaction between P-loop mutated RPP7bG195A/K196A and HR4Fei-0. The P-loop mutant RPP7bG195A/K196A retained the ability to associate with HR4Fei-0, as shown by co-IP (Figure S3B). However, RPP7bG195A/K196A did not form a higher-order complex in the presence of HR4Fei-0, as demonstrated with BNPAGE (Figure 3E). We thus conclude that RPP7b oligomerization occurs in two steps, beginning with HR4Fei-0 binding to RPP7b, followed by P-loop dependent conformational change and finally formation of a higher-order complex.

NLR conformational changes expose functional domains for participation in downstream signaling (Wang et al., 2019a, 2019b), and CC domains alone can often trigger immune signaling when expressed on their own (Casey et al., 2016; Cesari et al., 2016; Maekawa et al., 20l lb), even in the absence of an activating partner. To test whether the CC or any other RPP7b domain can induce a hypersensitive response, we transiently expressed CC, NB-ARC, LRR, CC-NB-ARC, and NB-ARC-LRR constructs in N. benthamiana. None of the domains of RPP7b elicited a hypersensitive response, regardless of the presence of HR4Fei-0 (Figure S3C and S3D). Furthermore, different from the full-length version of RPP7b, the autoactivating MHV mutation did not confer autoactivity on any of the truncated forms (Figure S3D). These results suggest that the integrity of all domains of RPP7b is required for functional complex assembly and initiation of signaling.

\section{Requirement of RPP7 LRRs for HR4Fei-0-induced RPP7 oligomerization}

The LRR domains of plant NLRs are often responsible for pathogen recognition and correspondingly polymorphic. Comparison of RPP7bLerik1-3 with other RPP7 variants (Van de Weyer et al., 2019) revealed various LRR domain insertions and deletions in the phylogenetic clade that includes RPP7bLerikl-3 (Figure 4A). Coexpression of HR4Fei-0 with RPP7Sf-2, which has the same LRR domain as RPP7blerikl-3, elicited a hypersensitive response in N. benthamiana, albeit more weakly than co-expression of RPP7bLerikl-3 (Figure 4B). Similarly, we found that RPP7Mrk-0, which is incompatible with RPW8.|KZ10, is distinguished from other RPP7 variants by a truncated LRR domain (Van de Weyer et al., 2019) (Figure S4A). The causality of the LRR truncation was 
bioRxiv preprint doi: https://doi.org/10.1101/682807; this version posted June 25,2019 . The copyright holder for this preprint (which was not certified by peer review) is the author/funder, who has granted bioRxiv a license to display the preprint in perpetuity. It is made available under aCC-BY 4.0 International license.

Li et al.

RPW8/HR proteins and plant NLR oligomerization

confirmed with RPP7Ty-1, which is very similar to RPP7Mrk-0, but which does not have a truncated LRR domain and thus is not incompatible with RPW8.IKZ10 (Figure S4B-E). FI plants derived from crosses between KZIO and six other accessions having RPP7 homologs with truncated LRR domains developed strong hybrid necrosis (100I Genomes Consortium, 2016) (Figure S4B). LRR truncation is, however, not sufficient for hybrid necrosis, as inferred from four further accessions carrying LRR-truncated RPP7 alleles that did not cause hybrid necrosis in crosses with KZIO (Figure S4B).

A

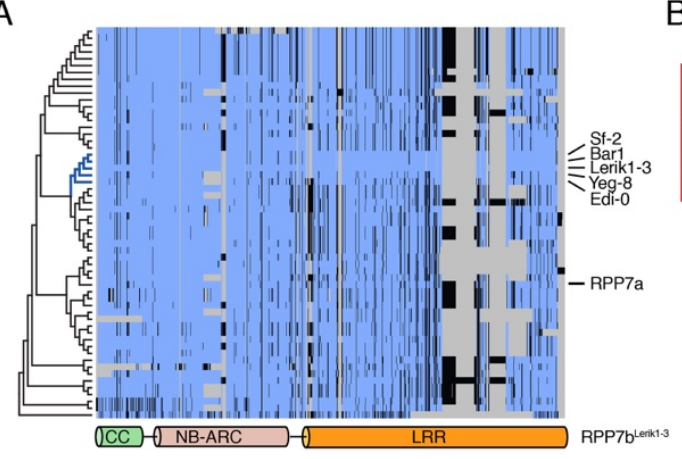

B

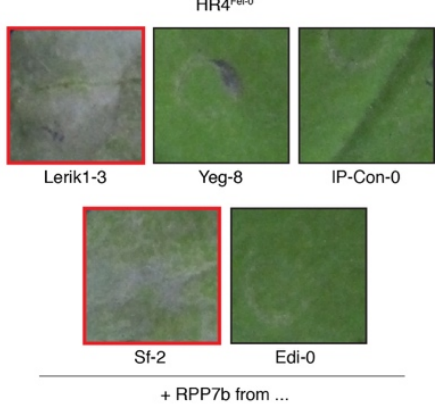

D

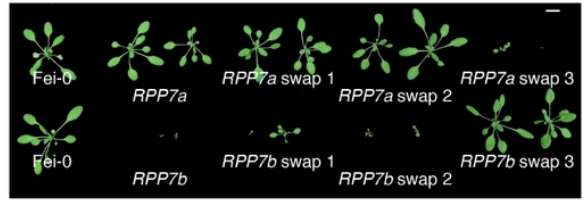

$\mathrm{F}$

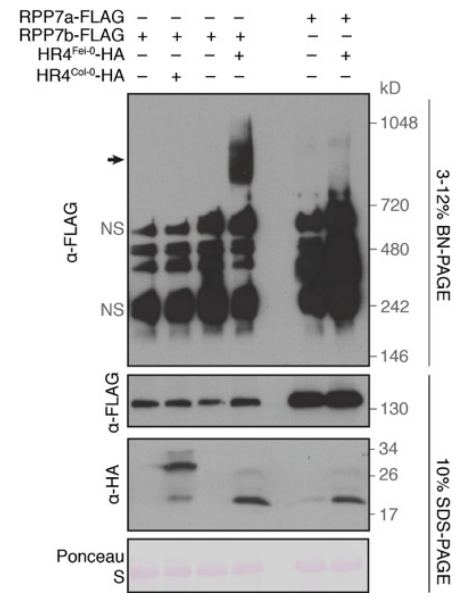

Figure 4. Requirement of RPP7 LRRs for HR4Fei-0-induced oligomerization of RPP7b

(A) Alignments of RPP7 related proteins from 64 accessions with RPP7b ${ }^{\text {Lerikl-3 }}$ reveal sequence and structural polymorphisms,

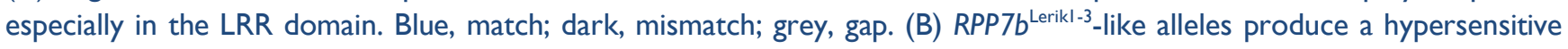
response (indicated by red frames) when co-expressed with HR4 $4^{\text {ei- }-0}$ in N. benthamiana, seven days after Agrobacterium infiltration. Experiments were performed at least three times. (C) Specific domain swaps between RPP7a and RPP7b, when co-expressed with $\mathrm{HR} 4^{\mathrm{Fe} i-0}$, can induce hypersensitive response (indicated by red frames) in N. benthamiana, seven days after Agrobacterium infiltration. Experiments were performed at least twice. (D) Four-week-old $T_{1}$ transgenic A. thaliana plants expressing chimeras from $(\mathrm{C})$ in Fei-0 background, grown at $23^{\circ} \mathrm{C}$. RPP7 swaps were under the control of the RPP7b promoter. Size bar corresponds to I cm. (E) HR4 ${ }^{\text {ei- } 0}$ specifically interacts with RPP7b in vivo, as shown by co-IP from transgenic A. thaliana plants. Expression of RPP7a-FLAG or RPP7b-FLAG under the control of its native promoter and HR4 $4^{\text {Fei- }}$ 

aCC-BY 4.0 International license.

${ }^{0}$-HA or HR4 ${ }^{\text {Col-0 }}$-HA was induced by $\beta$-estradiol. (F) HR4 ${ }^{\text {Fei-0 }}$ specifically induces the oligomerization of RPP7b, as shown by BN-PAGE and SDS-PAGE. Arrow points to RPP7b high-molecular weight complexes. NS indicates nonspecific bands. Experiments of $(E)$ and $(F)$ were performed at least twice.

To further dissect the function of different domains, we generated a series of RPP7aLerikl-3/RPP7bLerik I-3 chimeras. Swapping the CC or NB-ARC domains had no effect on either RPP7a or RPP7b activity (Figure 4C, S4F and S4G, swaps I and 2). In contrast, exchanging the LRR domains inactivated RPP7b (Figure 4C, RPP7b swap 3), while the RPP7b LRR domain was sufficient to impart necrosis-inducing activity on RPP7a (Figure 4C, RPP7a swaps 3). Transgenic A. thaliana plants further confirmed the results obtained with transient expression in $N$. benthamiana leaves (Figure 4D). Additional chimeras indicated that a largely intact LRR domain is required for RPW8/HR-dependent signaling and/or RPP7b protein stability (Figure S4F, S4H, S4I).

To investigate the mechanism underlying the specificity of HR4Fei-0/RPP7b signaling, we performed co-IPs with material from transgenic plants. These showed that HR4Fei-0 co-immunoprecipitated RPP7b more efficiently than RPP7a (Figure 4E), indicating that association of RPP7b with HR4Fei-0 is correlated with immune signaling. Preferential binding of HR4Fei-0 to the RPP7b LRR domain was further supported by co-IPs and pull-down assays (Figure S4J and S4K). Homology modeling of RPP7a and RPP7b LRR structures and superposition of these two structures suggested that the RPP7b LRR domain, which provides an interface for interaction with HR4Fei-0, has a more open conformation (Figure S4L). Finally, BN-PAGE showed that HR4Fei-0 cannot induce oligomerization of RPP7a (Figure 4F). We conclude that specific association between HR4Fei-0 and RPP7b, with the RPP7b LRR domain providing specificity for interaction with the HR4Fei-0 ligand, induces the oligomerization of RPP7b in vivo and initiates immune signaling.

\section{RPP7b-independent activity of HR4Fei-0}

The differences in genetic requirements for RPW8/HR and RPP7 signaling on their own (McDowell et al., 2000; Xiao et al., 2005) prompted us to test whether HR4Fei-0 proteins might have activity independently of RPP7 partners. Indeed, we found that while moderate expression of HR4Fei-0 in N. benthamiana could not induce a hypersensitive response without its RPP7b partner (Figure IA), strong overexpression of HR4Fei-0 could (Figure 5A). Further evidence for RPP7b-dependent and -independent activities of HR4Fei-0 came from structure-function studies: While even small $\mathrm{N}$-terminal deletions compromised the stand-alone activity of HR4Fei-0, these did not affect or even increased activity of HR4Fei-0 in the presence of RPP7b (Figure 5A). In contrast, C-terminal deletions had similar effects in the presence or absence of RPP7b (Figure 5A).

To further investigate RPP7b-independent activity of HR4Fei-0, we transformed a fusion of HR4Fei-0 with GFP, a large tag that can promote dimerization (Shaner et al., 2005), into the Col-0 background. We found that HR4::HR4Fei-0_GFP plants were often smaller, a phenotype shared with other autoimmune mutants (Figure 5B). These plants also had increased expression of the defense marker PRI, and proliferation of the model pathogen Pseudomonas syringae DC3000 was substantially reduced (Figure 5B). Together, these observations suggest that HR4Fei-0 can trigger (auto)immunity in an RPP7b-independent manner. 
A
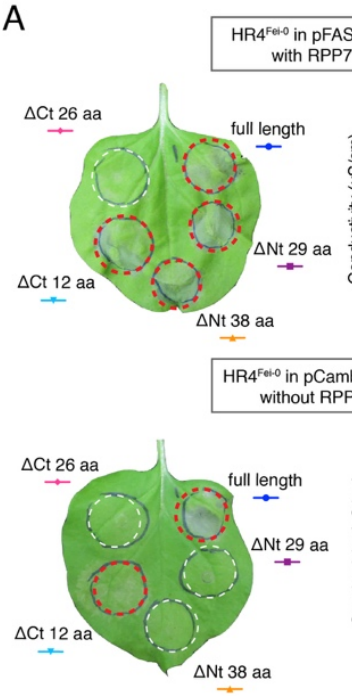

in pFAST-G02

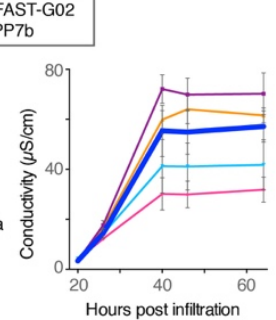

Hours post infiltration

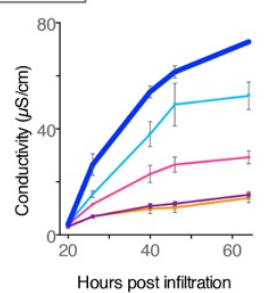

B
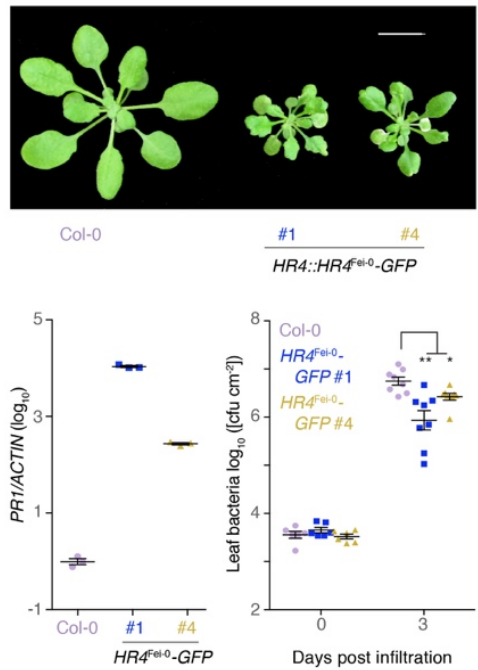

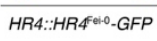

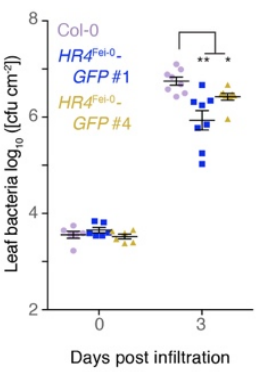

Figure 5. RPP7b-independent activity of HR4Fei-0

(A) Left, hypersensitive response (red circles) induced by expression of full-length or truncated HR4 ${ }^{\text {Fei- } 0}$ variants using PFASTG02 for moderate expression (top) and pCambial 300 for strong overexpression (bottom), and with or without RPP7b in $N$. benthamiana, four days after Agrobacterium infiltration. For control for PFAST-G02 expression of HR4 $4^{\text {Fei-0 }}$ in the absence of RPP7b, see Figure IA (experiment 7). Right panels, ion leakage measurements of plants shown on left. Values are means \pm SEM $(n=3)$. Each sample contains six leaf discs from different plants. Experiments were performed at least twice. (B) HR4::HR4 ${ }^{\text {Fei-0.-GFP }}$ reduces plant growth, induces $P R I$ defense marker and suppresses the bacterial model pathogen Pseudomonas syringae pv. tomato DC3000 ( $* \mathrm{P}<0.05$, **P $<0.0$ I, Student's $t$ test; $\mathrm{n}=8$ ).

\section{Aggregation of HR4Fei-0 contributes to its cell death activity}

While RPP7b is not required for cell death induced by HR4Fei-0 overexpression or enhanced HR4Fei-0 dimerization, we could not exclude that HR4Fei-0 in such contexts associates with other, unknown NLRs. To directly test the ability of HR4Fei-0 to compromise cell growth without any NLRs, we therefore turned to a heterologous system, expression in $E$. coli, which has also been used to investigate the cytotoxic activity of the fungal HELL domain protein Het-S (Seuring et al., 20I2). Expression of HR4Fei-0 strongly suppressed bacterial growth, and eventually reduced bacterial number, while HR4Col-0 had more modest effects on bacterial growth (Figure 6A). These experiments confirmed cytotoxicity of HR4Fei-0 , and to a lesser extent of HR4Col-0, in a heterologous system.

Het-S can form amyloidal aggregates that break down into detergent-resistant dimers and/or trimers (Mathur et al., 20I2). To test whether HR4 behaved similarly, we purified His-MBP-HR4 fusion proteins from E. coli and analyzed the proteins after removal of the MBP tag. We found that HR4Fei-0 could form stable, SDSresistant dimers or tetramers, but HR4Col-0 could not (Figure 6B). In addition, while both fusion proteins contained the same TEV protease cleavage site, the His-MBP-HR4Fei-0 fusion, was more resistant to TEV protease digestion than His-MBP-HR4Col-0. Finally, SDS-resistant dimers of HR4Fei-0 but not of HR4Col-0 were observed in N. benthamiana, paralleling their ability to induce cell death (Figure 6C). 
bioRxiv preprint doi: https://doi.org/10.1101/682807; this version posted June 25,2019 . The copyright holder for this preprint (which was not certified by peer review) is the author/funder, who has granted bioRxiv a license to display the preprint in perpetuity. It is made available under aCC-BY 4.0 International license.

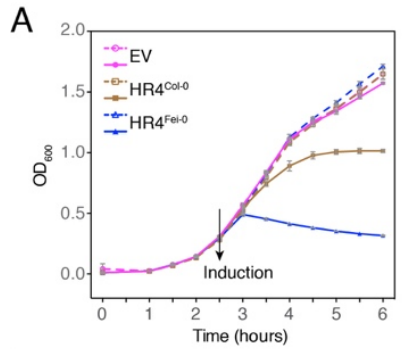

B

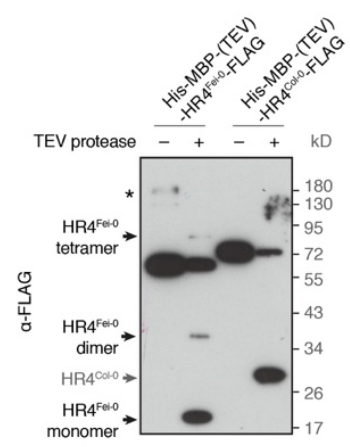

D

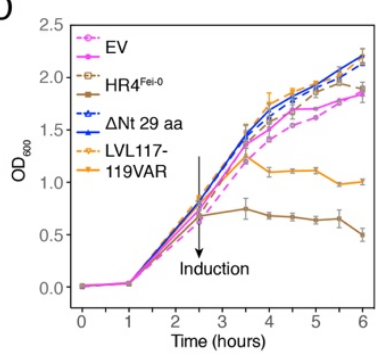

C

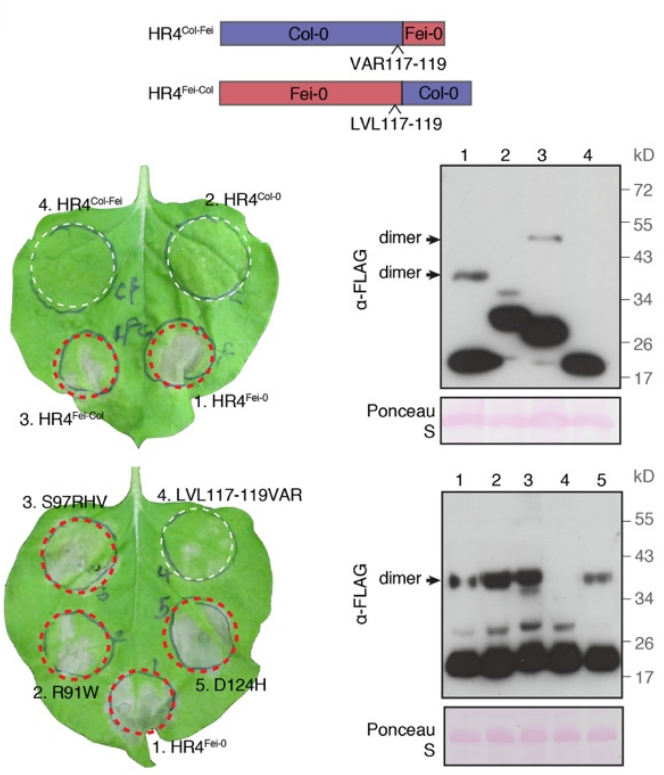

E

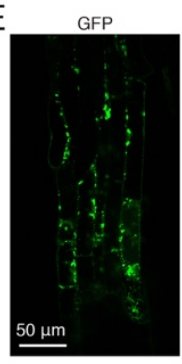

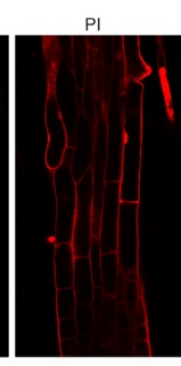

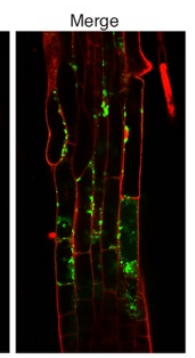

Figure 6. Aggregation of HR4Fei-0 contributes to its cytotoxic activity

(A) Expression of $\mathrm{HR}^{\mathrm{Fe} i \mathrm{-} 0}$ is toxic to E. coli. Bacterial growth was determined by $\mathrm{OD}_{600}$ measurement; expression of heterologous proteins was induced (solid lines) with $0.2 \mathrm{mM} \mathrm{IPTG}$ at $37^{\circ} \mathrm{C}$ at the same time for all cultures. Values are means $\pm \operatorname{SEM}(n=3)$. EV, empty vector. (B) Recombinant HR4 ${ }^{\text {Fei- } 0}$ but not HR4 ${ }^{\text {Col-0 }}$ protein forms SDS-resistant dimers and tetramers. The same amount, $3 \mu \mathrm{g}$, of His-MBP-(TEV) fusion proteins was incubated without or with $0.1 \mu \mathrm{g}$ TEV protease overnight at $4^{\circ} \mathrm{C}$. Compare major bands at $60-70 \mathrm{kD}$ for assessment of TEV protease cleavage efficiency. Asterisk indicates fusion protein oligomers. (C) HR4 domain swaps and targeted mutations. Left, hypersensitive response (red circles) induced by overexpression of domain swaps between HR4 ${ }^{\mathrm{Fei}-0}$ and HR4 $4^{\mathrm{Col}-0}$ (top) or mutated HR4 $4^{\mathrm{Fei}-0}$ (bottom) in N. benthamiana, four days after Agrobacterium infiltration. Right, protein accumulation for experiments shown of left. SDS-resistant dimers are indicated. Only the LVLI I7-I I VVAR mutation abrogates hypersensitive response and dimer formation. (D) Mutations of $\mathrm{HR} 4^{\text {Fei-0 }}$ that inhibit its cytotoxic activity in E. coli. Bacterial growth was determined by $\mathrm{OD}_{600}$ measurement; expression of heterologous proteins was induced (solid lines) with $0.2 \mathrm{mM} \mathrm{IPTG}$ at $37^{\circ} \mathrm{C}$ at the same time for all cultures. Values are means \pm SEM $(n=3)$. EV, empty vector. (E) Confocal images of an A. thaliana transgenic line expressing inducible HR4 ${ }^{\text {Fei-0 }}$-GFP after $10 \mathrm{~h}$ treatment with $\beta$-estradiol. The plasma membrane was stained with propidium iodide (PI).

In contrast to the critical role of HR4Fei- 0 C-terminal repeats in activation of hybrid necrosis in combination with RPP7b (Barragan et al., 2019), we found that replacing the C-terminal repeats of HR4Fei-0 with the HR4Col-0 repeats (HR4Fei-Col) only weakly affected its ability to form SDS-resistant dimers and to elicit cell death on its own. In contrast, swapping the $\mathrm{N}$-terminal domain (HR4Col-Fei) greatly reduced formation of SDS-resistant dimers and abrogated the ability to induce cell death (Figure 6C, top, and S6B). These results suggest that the $\mathrm{N}$-terminal domain of HR4Fei-0 determines its dimerization ability, and that dimerization in turn is required for its cytotoxic activity. Aggregation only, however, does not appear to be sufficient for the induction of cell death, since small 

aCC-BY 4.0 International license.

$\mathrm{N}$-terminal and C-terminal truncations did not impair the formation of SDS-resistant dimers (Figure S6A), but did affect the cytotoxic activity of HR4Fei-0 in planta (Figure 5A). We performed more fine-scale swaps and found that exchange of three consecutive amino acids, LII7V, VII8A, LII9R, in the HR4Fei-0 background reduced hypersensitive response and dimer formation in N. benthamiana (Figure 6C, bottom). In agreement, cytotoxic activity of HR4Fei-0 in E. coli was also attenuated by the LVLI I7-I I 9VAR mutation (Figure 6D). The N-terminal 29 amino acid deletion, which eliminated hypersensitive response in N. benthamiana (Figure 5A, bottom), also eliminated cytotoxic activity in E. coli (Figure 6D). Together, these results indicate that cell death-inducing activity of HR4Fei-0 in planta and in bacteria is structure dependent. The LVLI I7-I I 9 residues are located near the border of the $\mathrm{N}$-terminal domain and the $\mathrm{C}$-terminal repeats (Figure S6B), reminiscent of the short overlap between the HeLo and PFD domains of Het-S (Greenwald et al., 2010).

Finally, using a transgenic $A$. thaliana line that expresses the dimerization prone HR4Fei-0_GFP fusion protein under the control of an inducible promoter, we observed that HR4Fei-0_GFP accumulated as various-sized puncta that were localized at or close to the plasma membrane (Figure 6E), suggestive of aggregates formed in planta. In contrast, we could not detect such puncta with control transgenic lines expressing GFP only or HR4Col-0_GFP (Figure S6C). Some diffuse HR4Fei-0_GFP fluorescence was observed in the cytoplasm and around the nucleus (Figure S6C), which may correspond to Z-membranes, an artificial organelle formed by oligomerization of integral membrane proteins (Gong et al., 1996).

\section{DISCUSSION}

We have identified a two-pronged immunity signaling module with the enigmatic RPW8/HR proteins at its core. We took advantage of genetics and biochemistry to reveal the activation mechanism underlying HR4Fei-0/RPP7binduced plant immunity. Our data support a model in which HR4Fei-0 acts as a ligand that disrupts intramolecular association of RPP7b, which leads to its unfolding, thereby initiating oligomerization and finally immune signaling by RPP7b. In addition, we discovered that HR4Fei-0 on its own can trigger plant immunity, with distinct portions of the HR4Fei-0 molecule being involved in RPP7b-dependent and -independent immune signaling.

The first RPW8/HR protein to be functionally characterized was RPW8.2, because it provides immunity to powdery mildew fungi (Xiao et al., 200I). Constitutive expression of other RPW8/HR proteins endows plants with broad-spectrum resistance to both fungi and downy mildew oomycetes (Ma et al., 20l4). Such broadspectrum resistance, along with localization of several of these proteins to extrahaustorial membranes that form at the interface of plant epidermal cells and invading fungal cells, is suggestive of RPW8/HR proteins providing primary defenses against filamentous pathogens. However, the exact mode of action of different RPW8/HR proteins may differ, as indicated by RPW8.I accumulating around chloroplasts of mesophyll cells next to epidermal cells contacted by the fungus (Berkey et al., 2017; Wang et al., 2009),

An important observation is that HR4Fei-0 can cause autoimmunity even in the absence of the RPP7b partner. Homology modelling of RPW8/HR proteins has revealed striking similarity with MLKL and HELL domain 

aCC-BY 4.0 International license.

proteins, executors of cell death in animals and fungi (Bentham et al., 2018; Daskalov et al., 2016; Greenwald et al., 2010; Hildebrand et al., 20I4; Murphy et al., 20I3; Seuring et al., 20I2; Su et al., 20I4). The activity of both MLKL and Het-S is regulated by sequences immediately C-terminal to the domain shared by these proteins, corresponding to the $\mathrm{CC}_{\mathrm{R}}$ domain of RPW8/HR proteins (Chen et al., 20I4; Hildebrand et al., 20I4; Murphy et al., 2013; Seuring et al., 2012; Su et al., 20I4; Wang et al., 2014). Similar to the HELL domain protein Het-S (Seuring et al., 2012), expression of HR4Fei-0 is cytotoxic in bacteria, with RPP7b-independent activity of HR4Fei-0 likely being due to protein aggregation that is nucleated by C-terminal repeats (Figure 6). Variation in C-terminal repeats is also causal for hybrid necrosis activity of RPW8/HR variants in combination with specific RPP7 partners (Barragan et al., 2019), strongly suggesting that these repeats affect RPW8/HR conformation. While it was previously not possible to detect HR4 from Col-0 as a YFP fusion protein, even when expressed from a strong constitutive promoter (Berkey et al., 2017), we have been able to detect punctate aggregates that localize to the plasma membrane when HR4Fei-0 was expressed from an inducible promoter. Given that other RPW8/HR proteins localize to membranes, we propose that at least HR4Fei-0 and likely other proteins in this family have a direct role in triggering cell death by disrupting membrane integrity. This in turn may activate danger signals, including damage-associated molecular patterns (DAMPs), which would explain why RPW8/HR activity relies at least in part on well known immunity signaling pathways (Xiao et al., 2005).

Given that our work points to a direct role of HR4Fei-0 in inducing cell death (Figure 5 and 6), an attractive hypothesis is that because RPW8/HR proteins provide primary defenses against pathogens, they are targets of yet to be identified pathogen effectors and as such guardees that are monitored by NLRs including RPP7 as guards (Jones et al., 2016). We propose that RPW8/HR hybrid necrosis proteins such as RPW8.IKZI0 and HR4Fei-0 mimic other RPW8/HR proteins that have been modified by effectors and that are erroneously recognized by matching RPP7 variants. That the genetic requirements for RPP7Col-0 signaling in Hpa resistance (McDowell et al., 2000) differ from the genetic requirements for HR4Fei-0/RPP7bLerikI-3 autoimmunity (Figure ID) suggests, however, that not all RPP7 homologs depend on RPW8/HR partners. This is also consistent with the observation that RPP7Col-0_ mediated resistance to Hpa race Hiks I does not require HR4Col-0 (Barragan et al., 20I9). There is precedence for closely related NLR proteins or even the same NLR protein associating with different ligands or responding to different effectors (Lewis et al., 20I3; Seto et al., 20I7; Wang et al., 20I5).

Self-association plays an important role in the activation of plant NLR proteins (Bernoux et al., 20II; Casey et al., 2016; Cesari et al., 2016; Maekawa et al., 20l l b; Zhang et al., 20 I7b). The recent cryo-EM structures of plant ZARI and animal NLRC4 have greatly advanced our understanding of the biochemical mechanisms underlying NLR signaling (Hu et al., 20I5; Wang et al., 20I9a, 20I9b; Zhang et al., 20I5), even though the ZARI resistosome (or any other resistosome) has not yet been observed in vivo. In the in vitro ZARI resistosome, ZARI and RKSI exist as a heterodimer in the resting, inactive state. Similarly, in the NLRC4 inflammasome complex, both NLRC4 and the sensor NAIPs exist as monomers in the resting, inactive state. Upon activation, these plant and animal NLRs form higher-order complexes: in the NLRC4 case containing one NAIP and ten NLRC4 molecules, in the ZARI case containing five ZARI molecules. Our BN-PAGE results indicate that binding 

aCC-BY 4.0 International license.

of RPP7b to its autoactive ligand HR4Fei-0 induces oligomerization and formation of a higher-order complex, likely with predominantly six to seven RPP7b-HR4Fei-0 subunits ( 900 kD) (Figure 3D and 5F). We could not detect RPP7b in its monomeric form in vivo, regardless of the presence of HR4Fei-0. The size of inactive RPP7b protein as inferred by BN-PAGE is approximately twice its monomeric size (Figure 2D), suggesting that, similar to other plant NLRs, RPP7b hetero- or homodimers are formed before activation. In plant and animal NLR hetero-pairs, P-loop function of the sensor NLRs, such as RGA5, RRSI, and NAIP5, is dispensable for their activity (Césari et al., 20I4; Williams et al., 20I4; Zhao et al., 20II). In the ZARI resistosome, modification of the ZARI-RKSI complex by the PBL2UMP ligand triggers a large conformational change, resulting in allosterically driven release of ADP bound to the NB-ARC domain, and subsequent assembly of a pentameric ZARI-RKSI-PBL2UMP oligomer. In analogy with the activation of the ZARI resistosome, we propose that HR4Fei-0 induces RPP7b to form a higher-order complex in a P-loop dependent manner through direct interaction between the RPP7b LRR domain and HR4Fei-0. For this to occur, matching partners on both the RPW8/HR and on the RPP7 side are required.

In summary, we have investigated interactions between two arms of the plant immune system that have not been directly linked before, the CNL RPP7 and the non-NLR RPW8/HR proteins. We demonstrate that HR4Fei-0 protein can affect immune signaling both on its own and through its RPP7b partner. Our findings provide an excellent example of the usefulness of autoimmunity as a platform for mechanistic investigation of immune signaling.

\section{METHODS}

\section{Plant material and growth conditions}

Seeds of $A$. thaliana accessions and $N$. benthamiana were from laboratory stocks. A. thaliana plants were grown on soil at $23^{\circ} \mathrm{C}$ or $16^{\circ} \mathrm{C}$, at $65 \%$ relative humidity under $16 / 8 \mathrm{~h}$ (long days) or $8 / 16 \mathrm{~h}$ (short days) light/dark photoperiods with light ( 125 to $175 \mu \mathrm{mol} \mathrm{m}^{-2} \mathrm{~s}^{-1}$ ) provided by a I:I mixture of Cool White and Gro-Lux Wide Spectrum fluorescent lights (Luxline plus F36W/840, Sylvania, Erlangen, Germany). N. benthamiana plants were grown in short days at $23^{\circ} \mathrm{C}$ with same light intensity and humidity.

\section{Constructs and transgenic plants}

To generate constructs for protoplast transformation, fragments from cDNA were amplified by PCR and inserted into the PUC19-35S-FLAG-RBS and pUC19-35S-HA-RBS vectors (Li et al., 2005).

To generate constructs for recombinant proteins, HR4Fei-0 (30-Ct aa) or full length HR4Fei-0 was amplified and cloned into the pGEX-6p-I or pET-28a vector, respectively. RPP7a/bCC (I-I46 aa), RPP7a/bNB-ARC (I47-520 aa), RPP7a/bLRR (52I-Ct aa), were amplified from cDNA and inserted into the PETM-4I vector.

To generate genome editing vectors, plasmids with an A. thaliana codon optimized Cas 9 were assembled using the GreenGate system ( $\mathrm{Wu}$ et al., 2018a); Cas9-free transgenic seeds were selected by mCherry fluorescence in their seed coats. 

aCC-BY 4.0 International license.

To generate RPP7 and RPW8 constructs with plant promoters for transient expression or for stable transformation, all RPP7 variants with the RPP7b promoter (I,49I bP), RPW8. I KZI0 with native promoter (I,I22 bP), and HR4Fei-0 with native promoter ( I,I 78 bp) were amplified from corresponding genomic DNA. Fragments were inserted into a modified Gateway TOPO entry vector by ligation or Gibson assembly (New England Biolabs, NEB), and then transferred into pGWB or pFAST vectors (Nakagawa et al., 2007; Shimada et al., 20I0).

To generate constructs containing both RPP7 and HR4, fragments of genomic RPP7 with a promoter sequence from RPP7b ( I,49I bP) were inserted into the Gateway TOPO entry vector. The HR4 fragments with either a native promoter (I,I78 bp) or XVE inducible module from pER8 (Zuo et al., 2000) were then inserted into the above vector. Finally, the combined sequences were moved into the pFAST-G0I vector (Shimada et al., 2010).

Point mutations were introduced into the entry constructs described above by site-directed mutagenesis. Chimeric constructs were generated by Gibson assembly (New England Biolabs, NEB) based on above mentioned entry vectors.

\section{Transient expression and conductivity assay}

Four-week-old N. benthamiana plants were used for Agrobacterium tumefaciens-mediated transient expression. A. tumefaciens with different T-DNA vectors were grown overnight at $28^{\circ} \mathrm{C}$ to $\mathrm{OD}_{600}$ around 1.5 . Bacterial cells were harvested and resuspended in the induction buffer $(10 \mathrm{mM}$ MES [pH 5.7], $10 \mathrm{mM} \mathrm{MgCl}$ and I50 $\mu \mathrm{M}$ acetosyringone) with $\mathrm{OD}_{600}$ of 0.5 , and incubated in induction buffer at $28^{\circ} \mathrm{C}$ in a shaker for $2 \mathrm{~h}$. Bacterial inocula were mixed at I:I vol/vol ratio and infiltrated using a needleless syringe.

For conductivity assays, eight independent $N$. benthamiana leaves were injected with different bacteria.

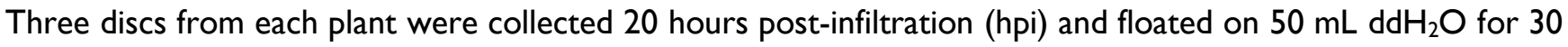
min. Leaf discs were transferred into tubes with $5 \mathrm{~mL} \mathrm{ddH_{2 }} \mathrm{O}$. Conductivity was measured using an Orion Conductivity Meter (Thermo Scientific, Beverly, MA, USA).

\section{Co-immunoprecipitation assays}

For anti-FLAG co-IPs with material from A. thaliana protoplasts, isolation and transformation of protoplasts were performed as previously described (Yoo et al., 2007). Total protein was extracted with $600 \mu \mathrm{L}$ extraction buffer (50 mM HEPES [pH 7.5], I 50 mM KCl, I mM EDTA [pH 8.0], 0.4\% Triton X- I00, I mM DTT, proteinase inhibitor cocktail), and incubated with $30 \mu \mathrm{L}$ ANTI-FLAG M2 Affinity agarose (Sigma-Aldrich, MO, USA) for $4 \mathrm{~h}$ at $4^{\circ} \mathrm{C}$. Agarose was washed seven times with extraction buffer without proteinase inhibitor cocktail, and bound protein was eluted with $60 \mu \mathrm{L}$ of $0.5 \mathrm{mg} / \mathrm{mL} 3 \times \mathrm{FLAG}$ peptide (Sigma-Aldrich, MO, USA) for I $\mathrm{h}$ at $4^{\circ} \mathrm{C}$. Proteins were separated by $10 \%$ SDS-PAGE and detected by immunoblot.

For anti-HA co-IP assays with material from A. thaliana plants, $100 \mathrm{mg}$ of 10 -day-old seedlings treated with or without $10 \mu \mathrm{M} \beta$-estradiol for $12 \mathrm{~h}$ were ground. Total protein was extracted with $600 \mu \mathrm{L}$ TBS extraction buffer (50 mM Tris- $\mathrm{HCl}$ [pH 7.5], I $50 \mathrm{mM} \mathrm{NaCl}$ I mM EDTA [pH 8.0], 0.4\% Triton X-100, proteinase inhibitor 

aCC-BY 4.0 International license.

cocktail), and incubated with $25 \mu \mathrm{L}$ anti-HA magnetic beads (Pierce, MA, USA) for $2 \mathrm{~h}$ at $4^{\circ} \mathrm{C}$. Beads were washed seven times with TBS extraction buffer without proteinase inhibitor, and the bound protein was eluted with 60 $\mu \mathrm{L}$ of $0.1 \mathrm{M}$ glycine $(\mathrm{pH} 2.2)$ for 10 min at room temperature and neutralized with $9 \mu \mathrm{L} \mathrm{I} \mathrm{M} \mathrm{Tris-HCl}(\mathrm{pH} 8.3)$. Proteins were separated by $10 \%$ SDS-PAGE and detected by immunoblot.

\section{Blue Native-PAGE}

Blue native polyacrylamide gel electrophoresis (BN-PAGE) was performed using the Bis-Tris NativePAGE system from Invitrogen (Carlsbad, CA, USA) according to the manufacturer's instructions. Briefly, eight I0-day-old seedlings were collected and ground in I N NativePAGE Sample Buffer (Invitrogen) containing I\% n-dodecyl $\beta$-Dmaltoside (DDM) and protease inhibitor cocktail, followed by $13,000 \mathrm{rpm}$ centrifugation for $20 \mathrm{~min}$ at $4^{\circ} \mathrm{C} .20$ $\mu \mathrm{L}$ supernatant mixed with I $\mu \mathrm{L}$ 5\% G-250 Sample Additive was loaded and run on a NativePAGE 3-I2\% Bis-Tris gel. Native gels were transferred to PVDF membranes (Millipore, Darmstadt, Germany) using NuPAGE Transfer Buffer, followed by protein blotting. For the second dimension of electrophoresis, a $5.7 \mathrm{~cm}$ strip of BN-PAGE gel was incubated in Laemmli sample buffer $(50 \mathrm{mM}$ Tris- $\mathrm{HCl}$ [pH 6.8], $100 \mathrm{mM} \mathrm{DTT,} 2 \%$ (w/v) SDS, 0.1\% bromophenol blue, 10\% (v/v) glycerol) for $10 \mathrm{~min}$, microwaved for $20 \mathrm{sec}$, and then rotated for another 5 min before loading the strip into the well of a NuPAGE 4-12\% Bis-Tris protein gel (Invitrogen).

\section{Recombinant protein purification and in vitro His pull-down}

Recombinant proteins were expressed in E. coli C4I cells. Bacterial cultures were induced by $0.4 \mathrm{mM}$ IPTG at $\mathrm{OD}_{600}$ of 0.4 at $20^{\circ} \mathrm{C}$ for $16 \mathrm{~h}$. GST-tagged and His-tagged proteins were affinity-purified using glutathione agarose beads (GE Healthcare, Pittsburgh, PA, USA) and Ni-NTA affinity agarose beads (QIAGEN, Venla, Netherlands) respectively, according to the manufacturer's instructions. Finally, the buffer of recombinant proteins were changed into a buffer containing $25 \mathrm{mM}$ Tris- $\mathrm{HCl}(\mathrm{pH} 7.5), 100 \mathrm{mM} \mathrm{NaCl}$, and I mM DTT using Amicon Ultra15 Centrifugal Filter Units (Millipore, Darmstadt, Germany).

For His pull-downs, $0.5 \mu \mathrm{g}$ His-MBP-tagged proteins, $2 \mu \mathrm{g}$ GST-HR4Fei-0, $20 \mu \mathrm{L}$ Ni-NTA affinity agarose beads were mixed in $500 \mu \mathrm{L}$ buffer $(25 \mathrm{mM}$ Tris- $\mathrm{HCl}[\mathrm{pH} 7.5], 150 \mathrm{mM} \mathrm{NaCl}, 0.2 \%$ Triton X-100, $20 \mathrm{mM}$ imidazole) and incubated at $4^{\circ} \mathrm{C}$ on a rotator for I $\mathrm{h}$. Agarose beads were washed seven times with the same buffer, and bound proteins were eluted by $60 \mu \mathrm{L}$ elution buffer $(25 \mathrm{mM}$ Tris- $\mathrm{HCl}$ [pH 7.5], I50 mM NaCl, 250 $\mathrm{mM}$ imidazole) for $15 \mathrm{~min}$ at $4^{\circ} \mathrm{C}$. Proteins were detected by immunoblot using anti-GST (Santa Cruz Biotechnology, Santa Cruz, CA, USA) and anti-His (Sigma-Aldrich, St. Louis, MO, USA) antibodies.

\section{Phylogenetic analysis}

RPP7 protein sequences were identified from an NLR Ren-seq data set (Van de Weyer et al., 2019) (http://annnblrrome.tuebingen.mpg.de/annotator/index) and aligned with Clustalx-2.I, either as full-length protein or trimmed NB-ARC domain. MEGA6 was used to reconstruct phylogenetic trees using Neighbor-Joining (NJ) method. Node confidence in NB-ARC domain-based tree was assessed by bootstrapping with I,000 replicates. 


\section{Confocal microscopy}

Transgenic 7-day-old A. thaliana seedlings were treated with $\beta$-estradiol for $10 \mathrm{~h}$ and imaged with a Zeiss LSM780NLO confocal microscope. Fluorescence was excited with the following wavelengths: $405 \mathrm{~nm}$ for 4',6diamidin-2-phenylindol (DAPI), $488 \mathrm{~nm}$ for GFP, and $56 \mathrm{I} \mathrm{nm}$ for propidium iodide (PI). Fluorescent signals were captured within the following emission wavelengths: 420 to $480 \mathrm{~nm}$ for DAPI, 500 to $540 \mathrm{~nm}$ for GFP, and 580 to $650 \mathrm{~nm}$ for PI. For DAPI and PI staining, seedings were submerged in $10 \mathrm{mg} / \mathrm{L} \mathrm{PI}$ and I mg/L DAPI for $5 \mathrm{~min}$, and then washed briefly in water before imaging.

\section{Accession numbers}

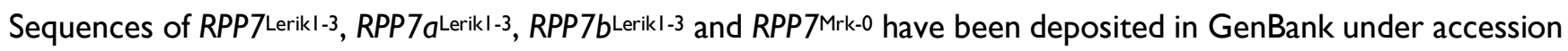
numbers MK776953-MK776956.

\section{ACKNOWLEDGMENTS}

We are most grateful to Cristina Barragan, Eunyoung Chae, Faird El-Kasmi, Thomas Lahaye, Thorsten Nürnberger, Rebecca Schwab, Bridgit Waithaka and Wangsheng Zhu for discussion and critical reading of the manuscript, to Cristina Barragan, Eunyoung Chae and Rui Wu for sharing plasmids and sequence information, and Johannes Stuttmann for sharing eds I- 12 seeds. Supported by an EMBO Long-term Fellowship (969-20I6 to L.L), an HFSP Long-term Fellowship (LT0003 I4/20I7-L to L.L), ERC Advanced Grant IMMUNEMESIS (340602), the DFG through Collaborative Research Center CRCI IOI and the Max Planck Society.

\section{AUTHOR CONTRIBUTIONS}

LL and DW designed the study. LL, AH and KW performed the experiments. $L L$ and DW analyzed the results. LL and DW wrote the paper.

\section{DECLARATION OF INTERESTS}

The authors declare no competing interests.

\section{REFERENCES}

I00I Genomes Consortium (2016). I, I35 Genomes Reveal the Global Pattern of Polymorphism in Arabidopsis thaliana. Cell I66, 48I-49I.

Aarts, N., Metz, M., Holub, E., Staskawicz, B.J., Daniels, M.J., and Parker, J.E. (1998). Different requirements for EDSI and NDRI by disease resistance genes define at least two R gene-mediated signaling pathways in Arabidopsis. Proc. Natl. Acad. Sci. U. S. A. 95, 10306-1031I.

Ade, J., DeYoung, B.J., Golstein, C., and Innes, R.W. (2007). Indirect activation of a plant nucleotide binding site-leucine- 
bioRxiv preprint doi: https://doi.org/10.1101/682807; this version posted June 25,2019 . The copyright holder for this preprint (which was not

certified by peer review) is the author/funder, who has granted bioRxiv a license to display the preprint in perpetuity. It is made available under aCC-BY 4.0 International license.

Li et al.

RPW8/HR proteins and plant NLR oligomerization

rich repeat protein by a bacterial protease. Proc. Natl. Acad. Sci. U. S. A. 104, 253 I-2536.

Barragan, C., Wu, R., Kim, S.-T., Xi, W., Habring, A., Hagmann, J., Van de Weyer, A.-L., Zaidem, M., Ho, W.W.H., Wang, G., et al. (2019). RPW8/HR Repeats Predict NLR-dependent Hybrid Performance.

Bentham, A.R., Zdrzalek, R., De la Concepcion, J.C., and Banfield, M.J. (20I8). Uncoiling CNLs: Structure/Function Approaches to Understanding CC Domain Function in Plant NLRs. Plant Cell Physiol. 59, 2398-2408.

Berkey, R., Zhang, Y., Ma, X., King, H., Zhang, Q., Wang, W., and Xiao, S. (2017). Homologues of the RPW8 Resistance Protein Are Localized to the Extrahaustorial Membrane that Is Likely Synthesized De Novo. Plant Physiol. I 73, 600613.

Bernoux, M., Ve, T., Williams, S., Warren, C., Hatters, D., Valkov, E., Zhang, X., Ellis, J.G., Kobe, B., and Dodds, P.N. (20II). Structural and functional analysis of a plant resistance protein TIR domain reveals interfaces for selfassociation, signaling, and autoregulation. Cell Host Microbe 9, 200-2II.

Bernoux, M., Burdett, H., Williams, S.J., Zhang, X., Chen, C., Newell, K., Lawrence, G.J., Kobe, B., Ellis, J.G., Anderson, P.A., et al. (2016). Comparative Analysis of the Flax Immune Receptors L6 and L7 Suggests an Equilibrium-Based Switch Activation Model. Plant Cell 28, 146-159.

Bonardi, V., Tang, S., Stallmann, A., Roberts, M., Cherkis, K., and Dangl, J.L. (20I I). Expanded functions for a family of plant intracellular immune receptors beyond specific recognition of pathogen effectors. Proc. Natl. Acad. Sci. U. S. A. I08, 16463-16468.

Cao, H., Glazebrook, J., Clarke, J.D., Volko, S., and Dong, X. (1997). The Arabidopsis NPRI gene that controls systemic acquired resistance encodes a novel protein containing ankyrin repeats. Cell 88, 57-63.

Casey, L.W., Lavrencic, P., Bentham, A.R., Cesari, S., Ericsson, D.J., Croll, T., Turk, D., Anderson, P.A., Mark, A.E., Dodds, P.N., et al. (2016). The CC domain structure from the wheat stem rust resistance protein $\mathrm{Sr} 33$ challenges paradigms for dimerization in plant NLR proteins. Proc. Natl. Acad. Sci. U. S. A. I 13, I2856-I286I.

Castel, B., Ngou, P.-M., Cevik, V., Redkar, A., Kim, D.-S., Yang, Y., Ding, P., and Jones, J.D.G. (20I8). Diverse NLR immune receptors activate defence via the RPW8-NLR NRG I. New Phytol.

Césari, S., Kanzaki, H., Fujiwara, T., Bernoux, M., Chalvon, V., Kawano, Y., Shimamoto, K., Dodds, P., Terauchi, R., and Kroj, T. (20I4). The NB-LRR proteins RGA4 and RGA5 interact functionally and physically to confer disease resistance. EMBO J. 33, I94I-1959.

Cesari, S., Moore, J., Chen, C., Webb, D., Periyannan, S., Mago, R., Bernoux, M., Lagudah, E.S., and Dodds, P.N. (20I6). Cytosolic activation of cell death and stem rust resistance by cereal MLA-family CC-NLR proteins. Proc. Natl. Acad. Sci. U. S. A. I /3, 10204-10209.

Chae, E., Bomblies, K., Kim, S.-T., Karelina, D., Zaidem, M., Ossowski, S., Martín-Pizarro, C., Laitinen, R.A.E., Rowan, B.A., Tenenboim, H., et al. (20l4). Species-wide genetic incompatibility analysis identifies immune genes as hot spots of deleterious epistasis. Cell 159, I34I-135I.

Chen, X., Li, W., Ren, J., Huang, D., He, W.-T., Song, Y., Yang, C., Li, W., Zheng, X., Chen, P., et al. (20I4). Translocation of mixed lineage kinase domain-like protein to plasma membrane leads to necrotic cell death. Cell Res. 24, I05-I2I.

Collier, S.M., Hamel, L.-P., and Moffett, P. (20I I). Cell death mediated by the N-terminal domains of a unique and highly conserved class of NB-LRR protein. Mol. Plant. Microbe. Interact. 24, 918-93I.

Dangl, J.L., and Jones, J.D.G. (2019). A pentangular plant inflammasome. Science 364, 3 I-32.

Daskalov, A., Habenstein, B., Sabaté, R., Berbon, M., Martinez, D., Chaignepain, S., Coulary-Salin, B., Hofmann, K., Loquet, A., and Saupe, S.J. (2016). Identification of a novel cell death-inducing domain reveals that fungal amyloid-controlled programmed cell death is related to necroptosis. Proc. Natl. Acad. Sci. U. S. A. I/ 3, 2720.

Ding, Y., Sun, T., Ao, K., Peng, Y., Zhang, Y., Li, X., and Zhang, Y. (2018). Opposite Roles of Salicylic Acid Receptors NPR I and NPR3/NPR4 in Transcriptional Regulation of Plant Immunity. Cell I73, I454-I467.

Dodds, P.N., Lawrence, G.J., Catanzariti, A.-M., Teh, T., Wang, C.-I.A., Ayliffe, M.A., Kobe, B., and Ellis, J.G. (2006). Direct protein interaction underlies gene-for-gene specificity and coevolution of the flax resistance genes and flax rust avirulence genes. Proc. Natl. Acad. Sci. U. S. A. 103, 8888-8893.

El Kasmi, F., Chung, E.-H., Anderson, R.G., Li, J., Wan, L., Eitas, T.K., Gao, Z., and Dangl, J.L. (20I7). Signaling from the 
bioRxiv preprint doi: https://doi.org/10.1101/682807; this version posted June 25,2019 . The copyright holder for this preprint (which was not

certified by peer review) is the author/funder, who has granted bioRxiv a license to display the preprint in perpetuity. It is made available under aCC-BY 4.0 International license.

Li et al,

RPW8/HR proteins and plant NLR oligomerization

plasma-membrane localized plant immune receptor RPMI requires self-association of the full-length protein. Proc. Natl. Acad. Sci. U. S. A. I/ 4, E7385-E7394.

Eulgem, T., Tsuchiya, T., Wang, X.-J., Beasley, B., Cuzick, A., Tör, M., Zhu, T., McDowell, J.M., Holub, E., and Dangl, J.L. (2007). EDM2 is required for RPP7-dependent disease resistance in Arabidopsis and affects RPP7 transcript levels. Plant J. 49, 829-839.

Gong, F.C., Giddings, T.H., Meehl, J.B., Staehelin, L.A., and Galbraith, D.W. (1996). Z-membranes: artificial organelles for overexpressing recombinant integral membrane proteins. Proc. Natl. Acad. Sci. U. S. A. 93, 2219-2223.

Greenwald, J., Buhtz, C., Ritter, C., Kwiatkowski, W., Choe, S., Maddelein, M.-L., Ness, F., Cescau, S., Soragni, A., Leitz, D., et al. (2010). The mechanism of prion inhibition by HET-S. Mol. Cell 38, 889-899.

Guo, Y.-L., Fitz, J., Schneeberger, K., Ossowski, S., Cao, J., and Weigel, D. (20II). Genome-wide comparison of nucleotide-binding site-leucine-rich repeat-encoding genes in Arabidopsis. Plant Physiol. 157, 757-769.

Hildebrand, J.M., Tanzer, M.C., Lucet, I.S., Young, S.N., Spall, S.K., Sharma, P., Pierotti, C., Garnier, J.-M., Dobson, R.C.J., Webb, A.I., et al. (2014). Activation of the pseudokinase MLKL unleashes the four-helix bundle domain to induce membrane localization and necroptotic cell death. Proc. Natl. Acad. Sci. U. S. A. I I I, I5072-15077.

Holt, B.F., 3rd, Belkhadir, Y., and Dangl, J.L. (2005). Antagonistic control of disease resistance protein stability in the plant immune system. Science 309, 929-932.

Hu, Z., Zhou, Q., Zhang, C., Fan, S., Cheng, W., Zhao, Y., Shao, F., Wang, H.-W., Sui, S.-F., and Chai, J. (2015). Structural and biochemical basis for induced self-propagation of NLRC4. Science 350, 399-404.

Hubert, D.A., He, Y., McNulty, B.C., Tornero, P., and Dangl, J.L. (2009). Specific Arabidopsis HSP90.2 alleles recapitulate RARI cochaperone function in plant NB-LRR disease resistance protein regulation. Proc. Natl. Acad. Sci. U. S. A. 106, 9556-9563.

Jones, J.D.G., Vance, R.E., and Dangl, J.L. (20I6). Intracellular innate immune surveillance devices in plants and animals. Science 354, aaf6395.

Jorgensen, T.H., and Emerson, B.C. (2008). Functional variation in a disease resistance gene in populations of Arabidopsis thaliana. Mol. Ecol. I 7, 49/2-4923.

Jubic, L.M., Saile, S., Furzer, O.J., El Kasmi, F., and Dangl, J.L. (2019). Help wanted: helper NLRs and plant immune responses. Curr. Opin. Plant Biol. 50, 82-94.

Krasileva, K.V., Dahlbeck, D., and Staskawicz, B.J. (2010). Activation of an Arabidopsis resistance protein is specified by the in planta association of its leucine-rich repeat domain with the cognate oomycete effector. Plant Cell 22, 2444-2458.

Lewis, J.D., Lee, A.H.-Y., Hassan, J.A., Wan, J., Hurley, B., Jhingree, J.R., Wang, P.W., Lo, T., Youn, J.-Y., Guttman, D.S., et al. (2013). The Arabidopsis ZEDI pseudokinase is required for ZARI-mediated immunity induced by the Pseudomonas syringae type III effector HopZI a. Proc. Natl. Acad. Sci. U. S. A. I I 0, 18722-I8727.

Li, X., Lin, H., Zhang, W., Zou, Y., Zhang, J., Tang, X., and Zhou, J.-M. (2005). Flagellin induces innate immunity in nonhost interactions that is suppressed by Pseudomonas syringae effectors. Proc. Natl. Acad. Sci. U. S. A. 102, I2990-I 2995.

Ma, X.-F., Li, Y., Sun, J.-L., Wang, T.-T., Fan, J., Lei, Y., Huang, Y.-Y., Xu, Y.-J., Zhao, J.-Q., Xiao, S., et al. (20I4). Ectopic expression of RESISTANCE TO POWDERY MILDEW8.I confers resistance to fungal and oomycete pathogens in Arabidopsis. Plant Cell Physiol. 55, 1484-1496.

Maekawa, T., Kufer, T.A., and Schulze-Lefert, P. (20l la). NLR functions in plant and animal immune systems: so far and yet so close. Nat. Immunol. I2, 8I7-826.

Maekawa, T., Cheng, W., Spiridon, L.N., Töller, A., Lukasik, E., Saijo, Y., Liu, P., Shen, Q.-H., Micluta, M.A., Somssich, I.E., et al. (20l lb). Coiled-coil domain-dependent homodimerization of intracellular barley immune receptors defines a minimal functional module for triggering cell death. Cell Host Microbe 9, 187-199.

Mathur, V., Seuring, C., Riek, R., Saupe, S.J., and Liebman, S.W. (2012). Localization of HET-S to the cell periphery, not to [Het-s] aggregates, is associated with [Het-s]-HET-S toxicity. Mol. Cell. Biol. 32, I39-I53.

McDowell, J.M., Cuzick, A., Can, C., Beynon, J., Dangl, J.L., and Holub, E.B. (2000). Downy mildew (Peronospora parasitica) resistance genes in Arabidopsis vary in functional requirements for NDRI, EDSI, NPRI and salicylic acid accumulation. Plant J. 22, 523-529. 
bioRxiv preprint doi: https://doi.org/10.1101/682807; this version posted June 25,2019 . The copyright holder for this preprint (which was not

certified by peer review) is the author/funder, who has granted bioRxiv a license to display the preprint in perpetuity. It is made available under aCC-BY 4.0 International license.

Li et al.

RPW8/HR proteins and plant NLR oligomerization

Mestre, P., and Baulcombe, D.C. (2006). Elicitor-mediated oligomerization of the tobacco $\mathrm{N}$ disease resistance protein. Plant Cell I8, 49I-50I.

Moffett, P., Farnham, G., Peart, J., and Baulcombe, D.C. (2002). Interaction between domains of a plant NBS-LRR protein in disease resistance-related cell death. EMBO J. $21,45 I I-45 I 9$.

Murphy, J.M., Czabotar, P.E., Hildebrand, J.M., Lucet, I.S., Zhang, J.-G., Alvarez-Diaz, S., Lewis, R., Lalaoui, N., Metcalf, D., Webb, A.I., et al. (20I3). The pseudokinase MLKL mediates necroptosis via a molecular switch mechanism. Immunity $39,443-453$.

Nakagawa, T., Kurose, T., Hino, T., Tanaka, K., Kawamukai, M., Niwa, Y., Toyooka, K., Matsuoka, K., Jinbo, T., and Kimura, T. (2007). Development of series of gateway binary vectors, pGWBs, for realizing efficient construction of fusion genes for plant transformation. J. Biosci. Bioeng. 104, 34-4I.

Nawrath, C., and Métraux, J.P. (1999). Salicylic acid induction-deficient mutants of Arabidopsis express PR-2 and PR-5 and accumulate high levels of camalexin after pathogen inoculation. Plant Cell II, I393-I 404.

Orgil, U., Araki, H., Tangchaiburana, S., Berkey, R., and Xiao, S. (2007). Intraspecific genetic variations, fitness cost and benefit of RPW8, a disease resistance locus in Arabidopsis thaliana. Genetics 176, 2317-2333.

Peart, J.R., Mestre, P., Lu, R., Malcuit, I., and Baulcombe, D.C. (2005). NRG I, a CC-NB-LRR protein, together with N, a TIR-NB-LRR protein, mediates resistance against tobacco mosaic virus. Curr. Biol. 15, 968-973.

Qi, D., and Innes, R.W. (20/3). Recent Advances in Plant NLR Structure, Function, Localization, and Signaling. Front. Immunol. 4, 348.

Qi, T., Seong, K., Thomazella, D.P.T., Kim, J.R., Pham, J., Seo, E., Cho, M.-J., Schultink, A., and Staskawicz, B.J. (20I8). NRGI functions downstream of EDSI to regulate TIR-NLR-mediated plant immunity in Nicotiana benthamiana. Proc. Natl. Acad. Sci. U. S. A. I I5, El0979-EI0987.

Rairdan, G.J., Collier, S.M., Sacco, M.A., Baldwin, T.T., Boettrich, T., and Moffett, P. (2008). The coiled-coil and nucleotide binding domains of the Potato $\mathrm{Rx}$ disease resistance protein function in pathogen recognition and signaling. Plant Cell 20, 739-75I.

Schreiber, K.J., Bentham, A., Williams, S.J., Kobe, B., and Staskawicz, B.J. (2016). Multiple Domain Associations within the Arabidopsis Immune Receptor RPPI Regulate the Activation of Programmed Cell Death. PLoS Pathog. I2, el 005769.

Seto, D., Koulena, N., Lo, T., Menna, A., Guttman, D.S., and Desveaux, D. (2017). Expanded type III effector recognition by the ZARI NLR protein using ZEDI-related kinases. Nat Plants 3, I 7027.

Seuring, C., Greenwald, J., Wasmer, C., Wepf, R., Saupe, S.J., Meier, B.H., and Riek, R. (2012). The mechanism of toxicity in HET-S/HET-s prion incompatibility. PLoS Biol. 10, el 00145 I.

Shaner, N.C., Steinbach, P.A., and Tsien, R.Y. (2005). A guide to choosing fluorescent proteins. Nat. Methods 2, 905-909.

Shimada, T.L., Shimada, T., and Hara-Nishimura, I. (2010). A rapid and non-destructive screenable marker, FAST, for identifying transformed seeds of Arabidopsis thaliana. Plant J. 6I, 519-528.

Steinbrenner, A.D., Goritschnig, S., and Staskawicz, B.J. (2015). Recognition and activation domains contribute to allelespecific responses of an Arabidopsis NLR receptor to an oomycete effector protein. PLoS Pathog. I I, e l004665.

Su, L., Quade, B., Wang, H., Sun, L., Wang, X., and Rizo, J. (2014). A plug release mechanism for membrane permeation by MLKL. Structure 22, 1489-1500.

Sukarta, O.C.A., Slootweg, E.J., and Goverse, A. (2016). Structure-informed insights for NLR functioning in plant immunity. Semin. Cell Dev. Biol. 56, I34-149.

Tameling, W.I.L., Vossen, J.H., Albrecht, M., Lengauer, T., Berden, J.A., Haring, M.A., Cornelissen, B.J.C., and Takken, F.L.W. (2006). Mutations in the NB-ARC domain of I-2 that impair ATP hydrolysis cause autoactivation. Plant Physiol. 140, $1233-1245$.

Tran, D.T.N., Chung, E.-H., Habring-Müller, A., Demar, M., Schwab, R., Dangl, J.L., Weigel, D., and Chae, E. (2017). Activation of a Plant NLR Complex through Heteromeric Association with an Autoimmune Risk Variant of Another NLR. Curr. Biol. 27, II48-II60.

Van de Weyer, A.-L., Monteiro, F., Furzer, O.J., Nishimura, M.T., Cevik, V., Witek, K., Jones, J.D.G., Dangl, J.L., Weigel, D., 
bioRxiv preprint doi: https://doi.org/10.1101/682807; this version posted June 25,2019 . The copyright holder for this preprint (which was not

certified by peer review) is the author/funder, who has granted bioRxiv a license to display the preprint in perpetuity. It is made available under aCC-BY 4.0 International license.

Li et al.

RPW8/HR proteins and plant NLR oligomerization

and Bemm, F. (2019). The Arabidopsis thaliana pan-NLRome. bioRxiv $53700 \mathrm{I}$.

Wagner, S., Stuttmann, J., Rietz, S., Guerois, R., Brunstein, E., Bautor, J., Niefind, K., and Parker, J.E. (2013). Structural basis for signaling by exclusive EDSI heteromeric complexes with SAGI0I or PAD4 in plant innate immunity. Cell Host Microbe 14, 619-630.

Wang, G., Roux, B., Feng, F., Guy, E., Li, L., Li, N., Zhang, X., Lautier, M., Jardinaud, M.-F., Chabannes, M., et al. (20I5). The Decoy Substrate of a Pathogen Effector and a Pseudokinase Specify Pathogen-Induced Modified-Self Recognition and Immunity in Plants. Cell Host Microbe 18, 285-295.

Wang, H., Sun, L., Su, L., Rizo, J., Liu, L., Wang, L.-F., Wang, F.-S., and Wang, X. (20I4). Mixed lineage kinase domain-like protein MLKL causes necrotic membrane disruption upon phosphorylation by RIP3. Mol. Cell 54, I33-I46.

Wang, J., Wang, J., Hu, M., Wu, S., Qi, J., Wang, G., Han, Z., Qi, Y., Gao, N., Wang, H.-W., et al. (2019a). Ligand-triggered allosteric ADP release primes a plant NLR complex. Science 364, eaav5868.

Wang, J., Hu, M., Wang, J., Qi, J., Han, Z., Wang, G., Qi, Y., Wang, H.-W., Zhou, J.-M., and Chai, J. (2019b). Reconstitution and structure of a plant NLR resistosome conferring immunity. Science 364, eaav5870.

Wang, W., Devoto, A., Turner, J.G., and Xiao, S. (2007). Expression of the membrane-associated resistance protein RPW8 enhances basal defense against biotrophic pathogens. Mol. Plant. Microbe. Interact. 20, 966-976.

Wang, W., Wen, Y., Berkey, R., and Xiao, S. (2009). Specific targeting of the Arabidopsis resistance protein RPW8.2 to the interfacial membrane encasing the fungal Haustorium renders broad-spectrum resistance to powdery mildew. Plant Cell 2I, 2898-2913.

Wildermuth, M.C., Dewdney, J., Wu, G., and Ausubel, F.M. (200I). Isochorismate synthase is required to synthesize salicylic acid for plant defence. Nature 4/4, 562-565.

Williams, S.J., Sornaraj, P., deCourcy-Ireland, E., Menz, R.I., Kobe, B., Ellis, J.G., Dodds, P.N., and Anderson, P.A. (20II). An autoactive mutant of the $M$ flax rust resistance protein has a preference for binding ATP, whereas wild-type $M$ protein binds ADP. Mol. Plant. Microbe. Interact. 24, 897-906.

Williams, S.J., Sohn, K.H., Wan, L., Bernoux, M., Sarris, P.F., Segonzac, C., Ve, T., Ma, Y., Saucet, S.B., Ericsson, D.J., et al. (2014). Structural basis for assembly and function of a heterodimeric plant immune receptor. Science 344, 299-303.

Wu, C.-H., Abd-El-Haliem, A., Bozkurt, T.O., Belhaj, K., Terauchi, R., Vossen, J.H., and Kamoun, S. (2017). NLR network mediates immunity to diverse plant pathogens. Proc. Natl. Acad. Sci. U. S. A. 30, 8I I3-8II8.

Wu, R., Lucke, M., Jang, Y.-T., Zhu, W., Symeonidi, E., Wang, C., Fitz, J., Xi, W., Schwab, R., and Weigel, D. (2018a). An efficient CRISPR vector toolbox for engineering large deletions in Arabidopsis thaliana. Plant Methods I4, 65.

Wu, Z., Li, M., Dong, O.X., Xia, S., Liang, W., Bao, Y., Wasteneys, G., and Li, X. (20I8b). Differential regulation of TNLmediated immune signaling by redundant helper CNLs. New Phytol.

Xiao, S., Ellwood, S., Calis, O., Patrick, E., Li, T., Coleman, M., and Turner, J.G. (200I). Broad-spectrum mildew resistance in Arabidopsis thaliana mediated by RPW8. Science 29I, II8-120.

Xiao, S., Emerson, B., Ratanasut, K., Patrick, E., O'Neill, C., Bancroft, I., and Turner, J.G. (2004). Origin and maintenance of a broad-spectrum disease resistance locus in Arabidopsis. Mol. Biol. Evol. 2I, 166I-1672.

Xiao, S., Calis, O., Patrick, E., Zhang, G., Charoenwattana, P., Muskett, P., Parker, J.E., and Turner, J.G. (2005). The atypical resistance gene, RPW8, recruits components of basal defence for powdery mildew resistance in Arabidopsis. Plant J. $42,95-110$.

Xu, F., Cheng, Y.T., Kapos, P., Huang, Y., and Li, X. (2014). P-loop-dependent NLR SNCI can oligomerize and activate immunity in the nucleus. Mol. Plant 7, I80I-1804.

Yoo, S.-D., Cho, Y.-H., and Sheen, J. (2007). Arabidopsis mesophyll protoplasts: a versatile cell system for transient gene expression analysis. Nat. Protoc. 2, I565-1572.

Zhang, L., Chen, S., Ruan, J., Wu, J., Tong, A.B., Yin, Q., Li, Y., David, L., Lu, A., Wang, W.L., et al. (20I5). Cryo-EM structure of the activated NAIP2-NLRC4 inflammasome reveals nucleated polymerization. Science 350, 404-409.

Zhang, M., Kadota, Y., Prodromou, C., Shirasu, K., and Pearl, L.H. (20I0). Structural basis for assembly of Hsp90-Sgt ICHORD protein complexes: implications for chaperoning of NLR innate immunity receptors. Mol. Cell 39, 269-28I. 
bioRxiv preprint doi: https://doi.org/101101/682807; this version posted June 25, 2019. The copyright holder for this preprint (which was not certified by peer review) is the author/funder, who has granted bioRxiv a license to display the preprint in perpetuity. It is made available under aCC-BY 4.0 International license.

Li et al.

RPW8/HR proteins and plant NLR oligomerization

Zhang, X., Dodds, P.N., and Bernoux, M. (20I7a). What Do We Know About NOD-Like Receptors in Plant Immunity? Annu. Rev. Phytopathol. 55, 205-229.

Zhang, X., Bernoux, M., Bentham, A.R., Newman, T.E., Ve, T., Casey, L.W., Raaymakers, T.M., Hu, J., Croll, T.I., Schreiber, K.J., et al. (20I7b). Multiple functional self-association interfaces in plant TIR domains. Proc. Natl. Acad. Sci. U. S. A. I I 4, E2046-E2052.

Zhao, Y., Yang, J., Shi, J., Gong, Y.-N., Lu, Q., Xu, H., Liu, L., and Shao, F. (20I I). The NLRC4 inflammasome receptors for bacterial flagellin and type III secretion apparatus. Nature 477, 596-600.

Zuo, J., Niu, Q.W., and Chua, N.H. (2000). Technical advance: An estrogen receptor-based transactivator XVE mediates highly inducible gene expression in transgenic plants. Plant J. 24, 265-273. 


\section{Supplemental Information}

A
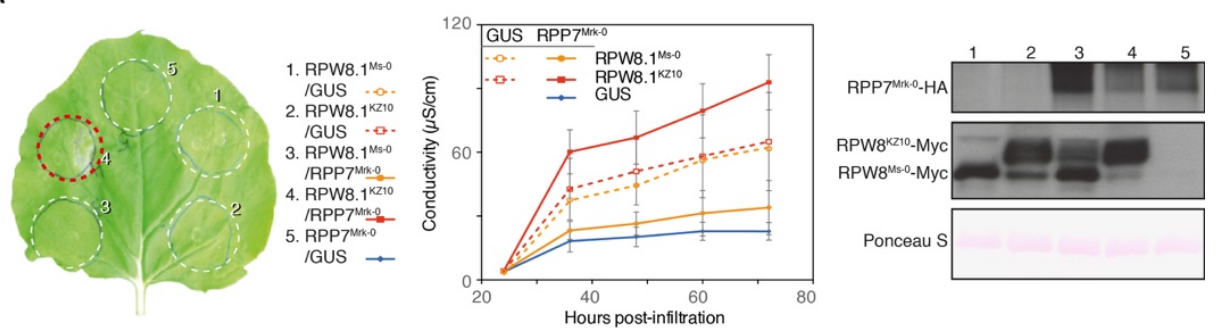

B
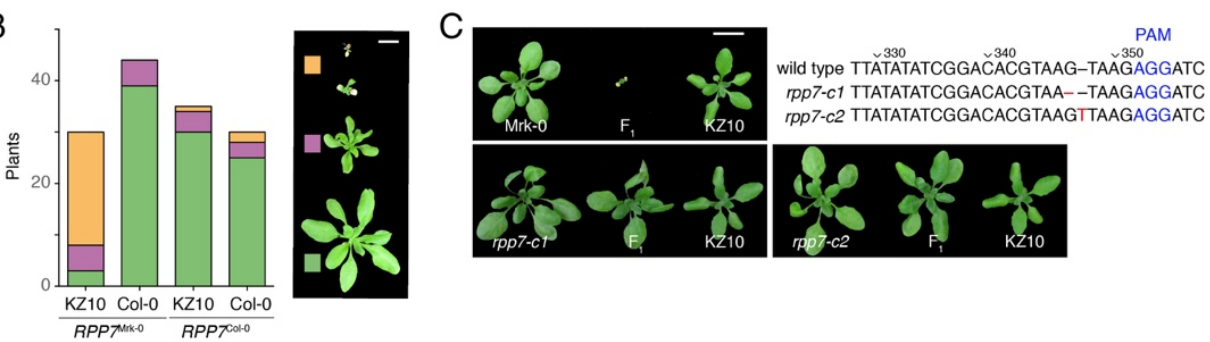

$\mathrm{D}$

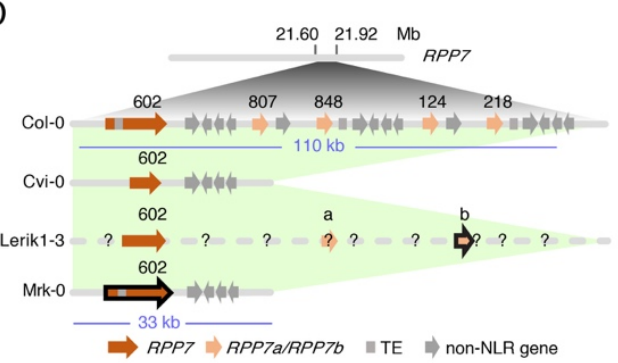

$E$

$\mathrm{F}$
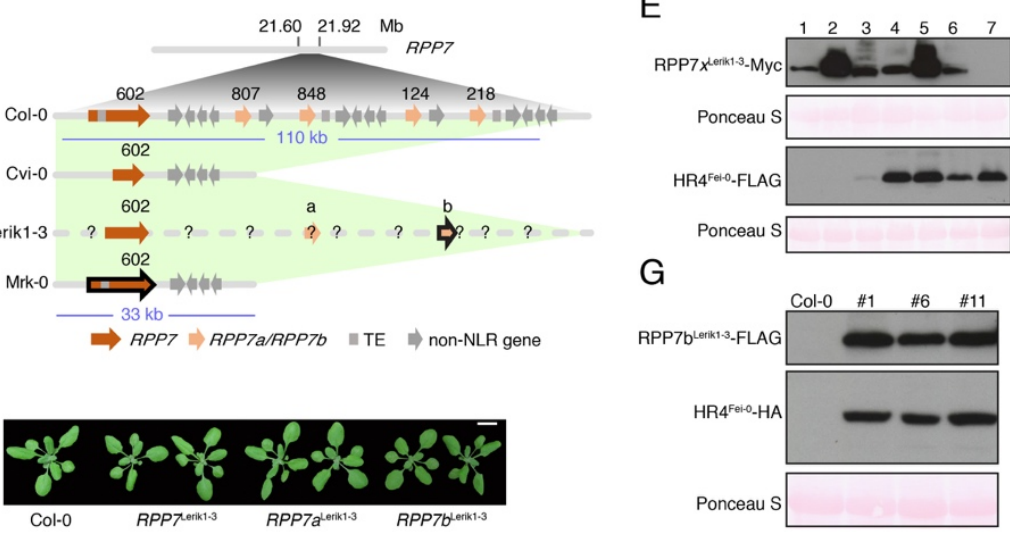

Figure S I. Identification of two distinct RPP7 alleles as causal for hybrid necrosis

(A) Left, hypersensitive response (indicated by red frames) induced by co-expression of RPP7Mrk-0 with RPW8KZ10 in N. benthamiana, four days after Agrobacterium infiltration. Experiments were performed at least three times. Middle, lon leakage measurements of plants shown on left. Values are means \pm SEM $(n=3)$. Each sample contains eight leaf discs from different plants, and experiments were performed at least twice. Right, protein accumulation as determined by immunoblot for experiments on left. (B) Recapitulation of Mrk- $0 \times$ $\mathrm{KZIO}$ hybrid phenotype in four-week-old $A$. thaliana $\mathrm{T}_{\text {I }}$ transgenic plants, grown in $23^{\circ} \mathrm{C}$. Size bar corresponds to I cm. (C) Requirement of RPP7Mrk-0 for hybrid necrosis demonstrated with CRISPR/Cas9-induced mutants, grown at $16^{\circ} \mathrm{C}$. Two of the KZ10 control plants shown are identical, because $F_{1} s$ were grown at the same time. Size bar corresponds to $\mathrm{I} \mathrm{cm}$. Mutations generated by CRISPR/Cas9 methodology are indicated. (D) RPP7 clusters of four A. thaliana accessions. The two causal alleles in Lerik I-3 and Mrk-0 are outlined in black. Numbers above arrows indicate Atlg58602, Atlg58807, Atlg58848, Atlg59I 24 and At lg592 18. The DNA sequences of At Ig58807Col-0 and At Ig59/24Col-0 are identical, as are the DNA sequences of At Ig58848 Col-0 and At lg592 I8Col-0. TE, transposon. (E) Protein accumulation as determined by immunoblot for experiments in Figure IA; see Figure IA for numbering. (F) Four-week-old $\mathrm{T}_{\text {I }}$ transgenic plants expressing RPP7 genes from Lerik -3 in the neutral Col-0 background, grown at $23^{\circ} \mathrm{C}$. (G) Protein expression for three

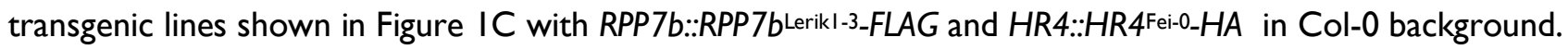


bioRxiv preprint doi: https://doi.org/10.1101/682807; this version posted June 25,2019 . The copyright holder for this preprint (which was not certified by peer review) is the author/funder, who has granted bioRxiv a license to display the preprint in perpetuity. It is made available under aCC-BY 4.0 International license.

A

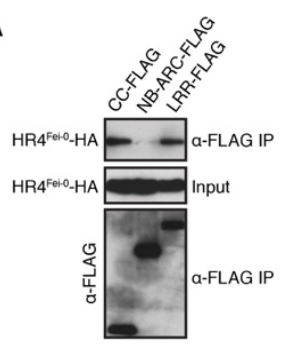

B

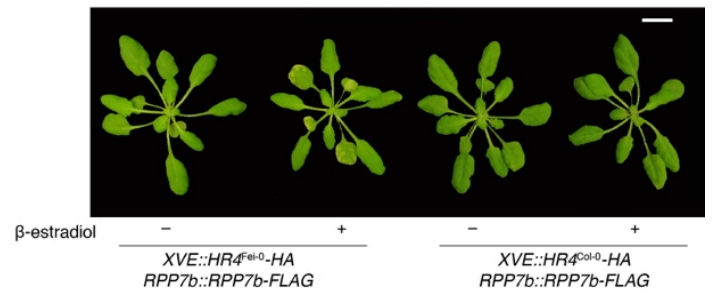

Figure S2. Association of HR4Fei-0 with RPP7b

(A) HR4Fei-0 interacts with CC and LRR domains of RPP7b in vivo, as shown by co-IP from A. thaliana protoplasts. (B) Transgenic A. thaliana plants used in Figure 2C, 2D and 2E, seven days after treatment with $\beta$ estradiol. 

aCC-BY 4.0 International license.
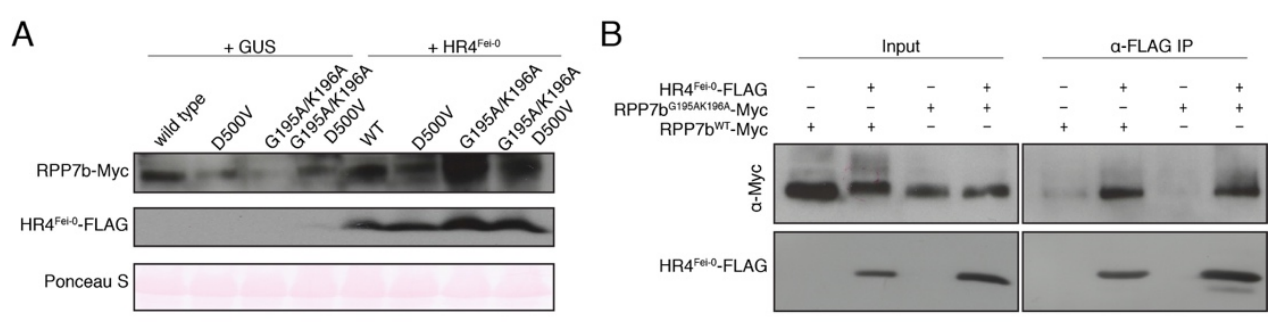

C

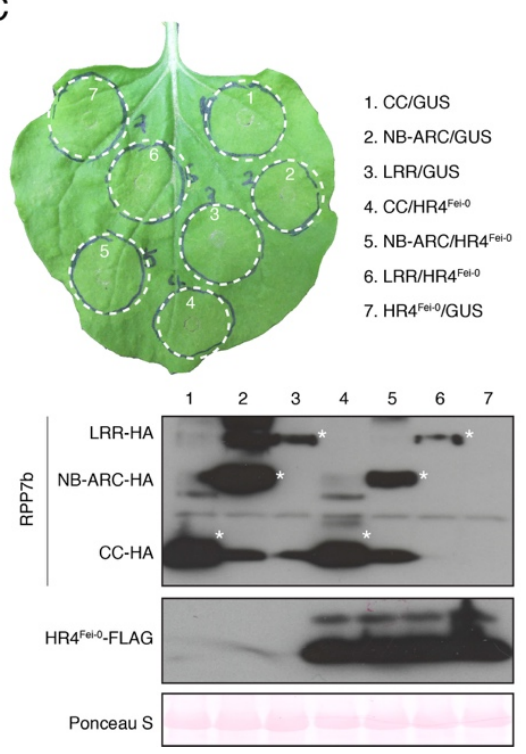

D

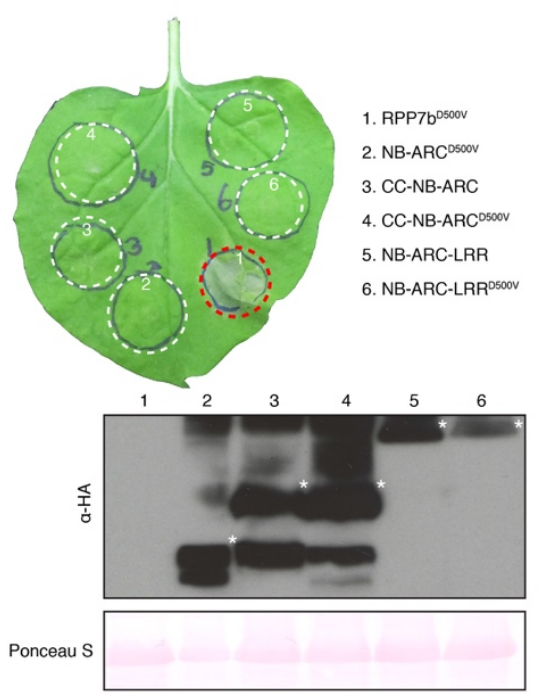

Figure S3. Protein accumulation of HR4Fei-0 and RPP7b variants

(A) Protein accumulation of P-loop and MHD motif mutants of RPP7b and of HR4Fei-0 in N. benthamiana, two days after Agrobacterium infiltration. Functional analyses shown in Figure 3C. (B) Interaction of HR4Fei-0 with Ploop mutant RPP7b variant, as shown by co-IP from N. benthamiana, two days after Agrobacterium infiltration. (C) Full-length RPP7b is required for activation of immune signaling. Top, lack of hypersensitive response induction by HA-tagged RPP7b domains in the presence or absence of HR4Fei-0-FLAG. Bottom, protein accumulation for experiments shown above. Asterisks indicate bands of the expected size. (D) MHD mutation in RPP7b NB-ARC domain is insufficient for hypersensitive response. Top, lack of hypersensitive response induction by RPP7b NB-ARC domain variants with MHD mutation D500V. RPP7bD500V was used as a positive control. Bottom, protein accumulation for experiments shown above. Asterisks indicate the bands of the expected size. RPP7bD500v-HA, even though clearly phenotypically active, was undetectable, most likely because of rapid degradation after autoactivation. 
bioRxiv preprint doi: https://doi.org/10.1101/682807; this version posted June 25, 2019. The copyright holder for this preprint (which was not certified by peer review) is the author/funder, who has granted bioRxiv a license to display the preprint in perpetuity. It is made available under aCC-BY 4.0 International license.

A

B
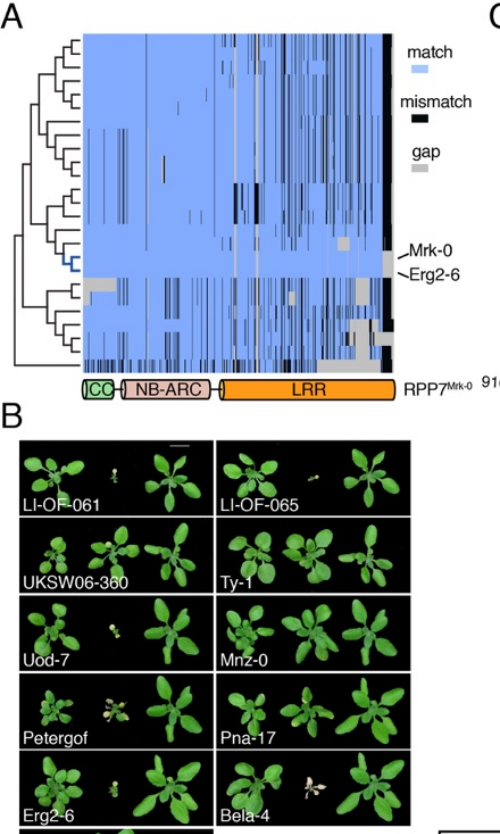

C

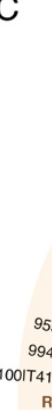

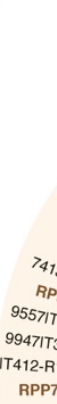

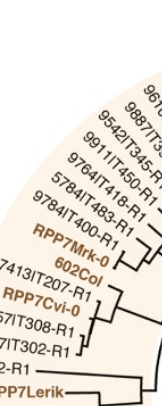

递酸
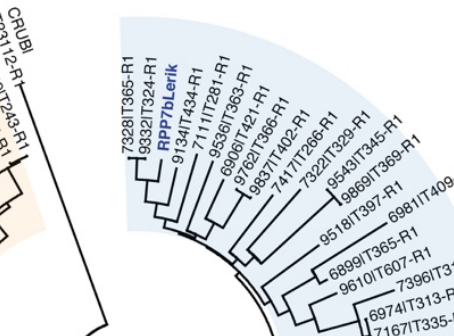

4161T288-R1 74161T288-R1 19251T512-R1
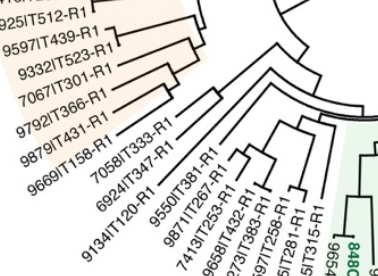

E
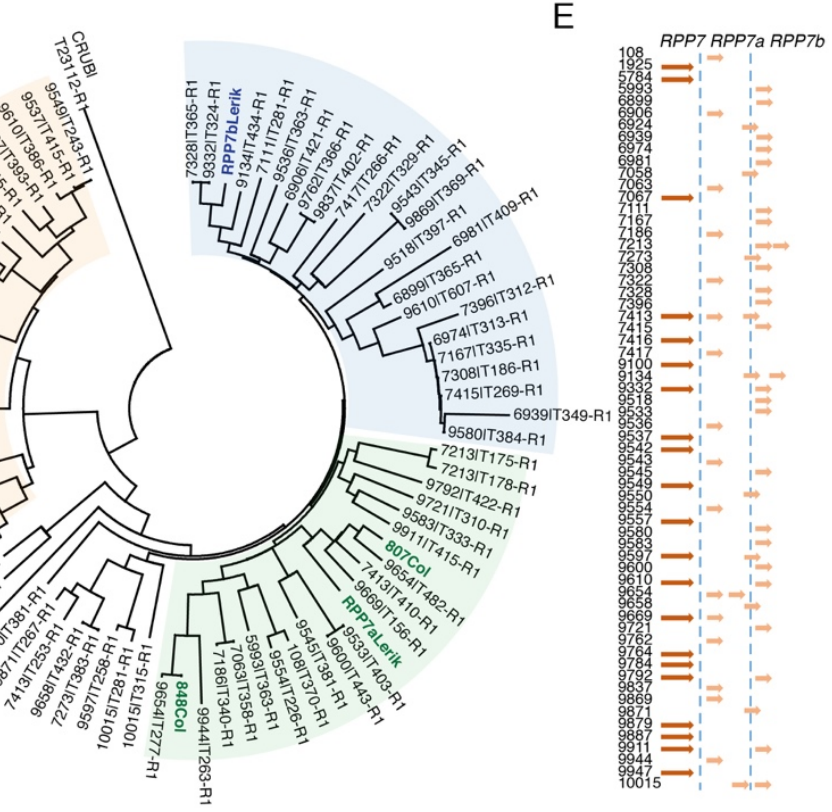

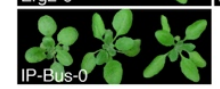

D

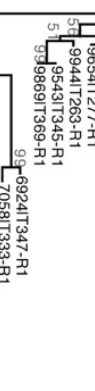

CC domentin

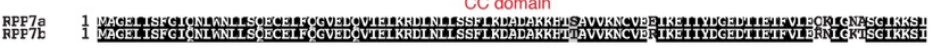

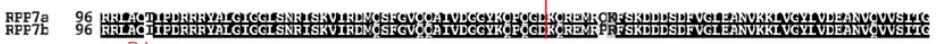

RPp7a 191 P- Ploop

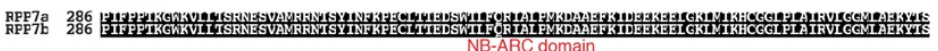

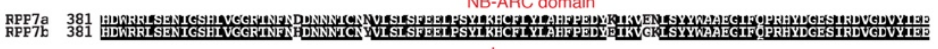

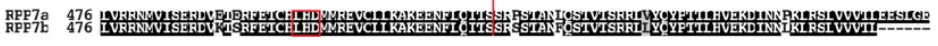

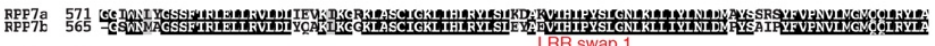

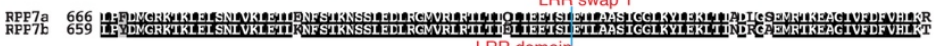

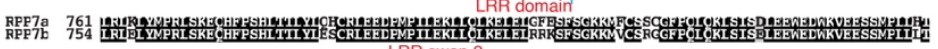

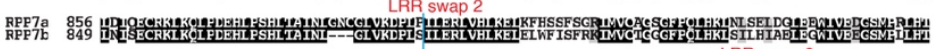

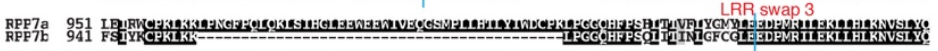

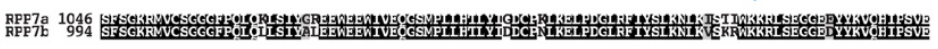
RPp7a 1141
RPF7b 1089

I
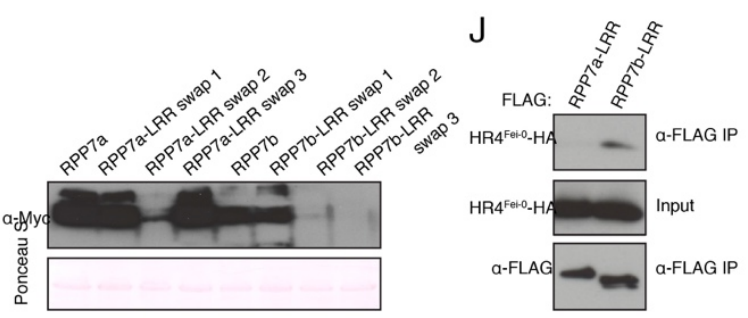
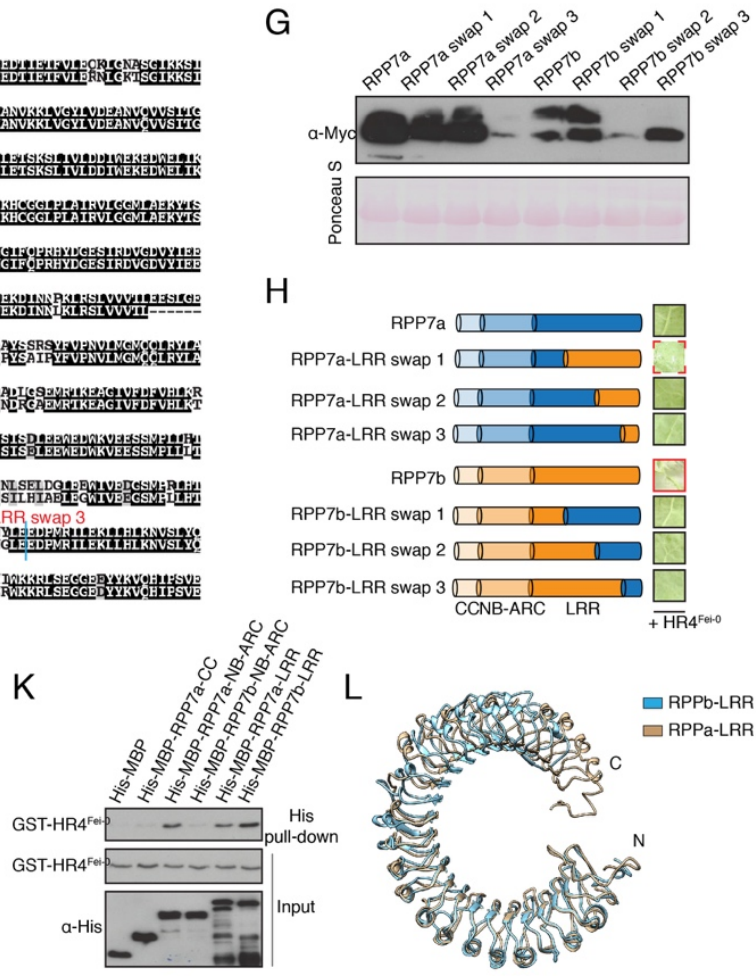

$\mathrm{H}$
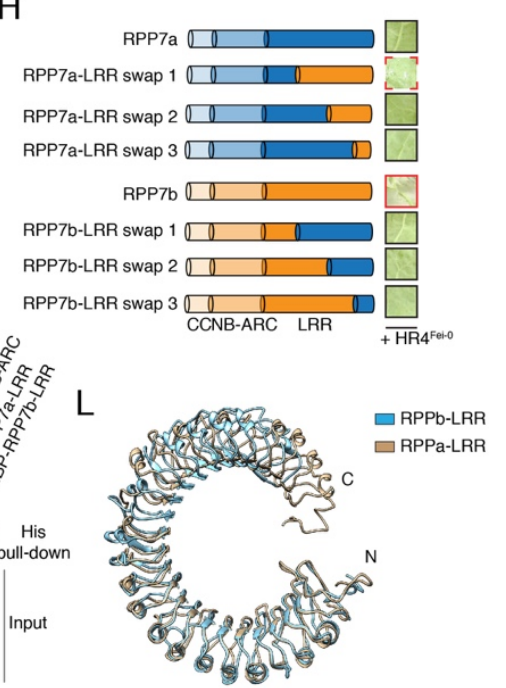

Figure S4. Requirement of RPP7 LRRs for HR4Fei-0-induced oligomerization 

aCC-BY 4.0 International license.

(A) Alignments of RPP7 related proteins from 64 accessions with RPP7Mrk-0 reveal sequence and structural polymorphisms, especially in the LRR domain. (B) Several accessions with RPP7b Mrk-0-like alleles produce hybrid necrosis when crossed to KZIO. $\mathrm{F}_{1}$ hybrids (middle) and different accessions (left) grown at $16^{\circ} \mathrm{C}$. Some of the KZIO control plants shown (always on the right) are identical, because several $F_{1} s$ were grown at the same time. Size bar corresponds to $\mathrm{I} \mathrm{cm}$. (C) Phylogeny of RPP7 full-length protein sequences from 64 accessions. Brown, RPP7Col-0/Mrk-0 clade; green, RPP7aLerikl-3 clade; blue, RPP7b ${ }^{L e r i k 1-3}$ clade. (D) Phylogeny of RPP7 NB-ARC domain sequences from 64 accessions. Bootstrap support out of 100 given in grey. (E) RPP7 copy number variation in different accessions. RPP7a and RPP7b subclades are based on the phylogeny in (A). (F) Protein sequence alignment between RPP7a and RPP7b to indicate domain boundaries used for domain swaps. (G) Protein accumulation as determined by immunoblot for experiments shown in Figure 4A. $(\mathrm{H})$ Hypersensitive response (red frames) induced by co-expression of HR4Fei- 0 and domain swaps between RPP7a and RPP7b LRR domains in $N$. benthamiana, seven days after Agrobacterium infiltration. Experiments were performed at least twice. (I) Protein accumulation as determined by immunoblot for experiments in $(\mathrm{H}) .(\mathrm{J})$ HR4Fei-0 interacts more effectively with the RPP7bLRR than the RPP7aLRR domain, as shown by co-IP from A. thaliana protoplasts. (K) HR4Fei-0 interacts more strongly with the RPP7bLRR than the RPP7aLRR domain in vitro, as shown by pull-down assays with proteins purified from E. coli. (L) Superposition of homology models of RPP7a and RPP7b LRR structures. 
bioRxiv preprint doi: https://doi.org/10.1101/682807; this version posted June 25,2019 . The copyright holder for this preprint (which was not certified by peer review) is the author/funder, who has granted bioRxiv a license to display the preprint in perpetuity. It is made available under aCC-BY 4.0 International license.
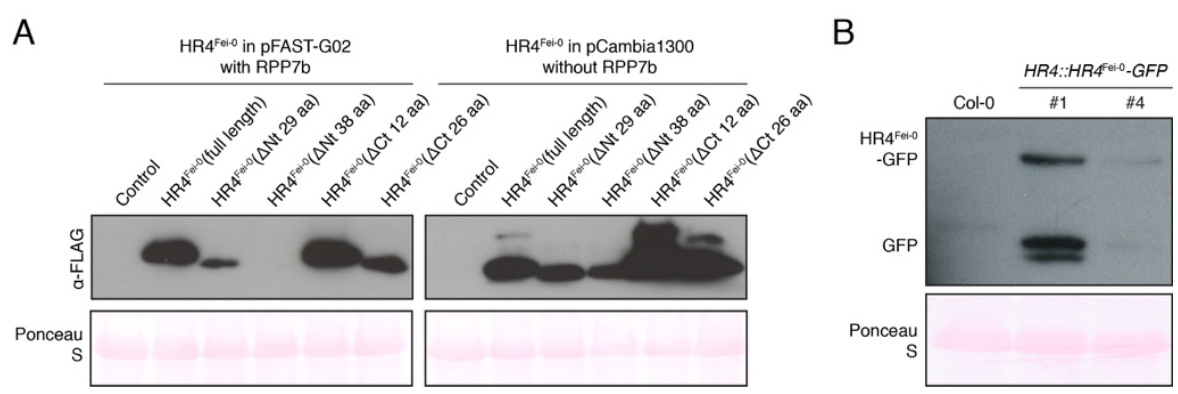

\section{Figure S5. RPP7b-independent activity of HR4Fei-0}

(A) Protein accumulation as determined by immunoblot for experiments in Figure 5A. (B) Protein accumulation as determined by immunoblot for transgenic $A$. thaliana lines in Figure $5 B$. 

aCC-BY 4.0 International license.
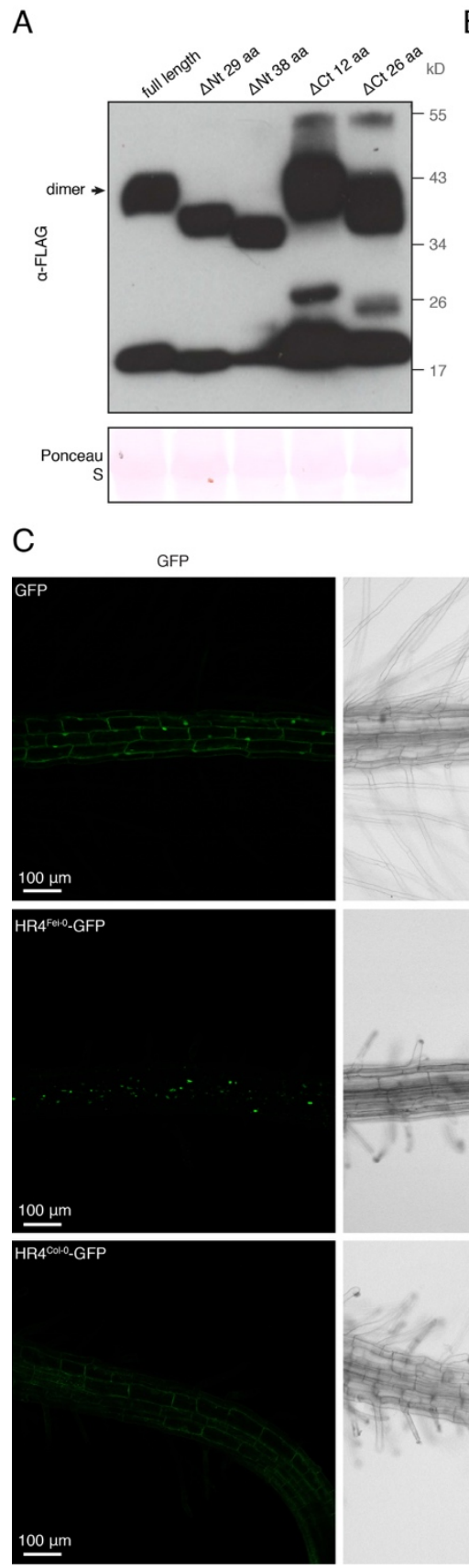

B
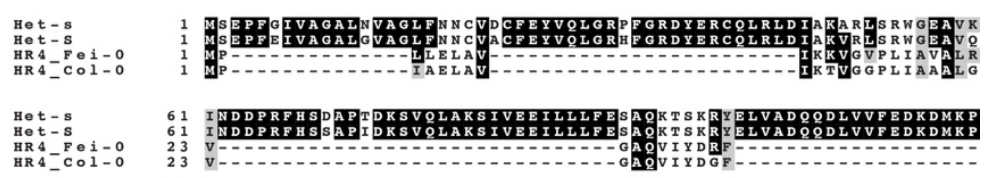

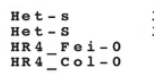

Het-s
Het-s
HR4-Fei-o
HR 4 - Col-o

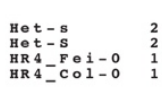

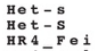

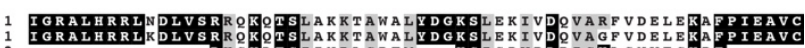

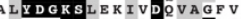

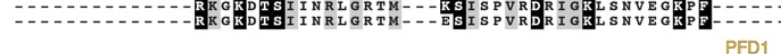
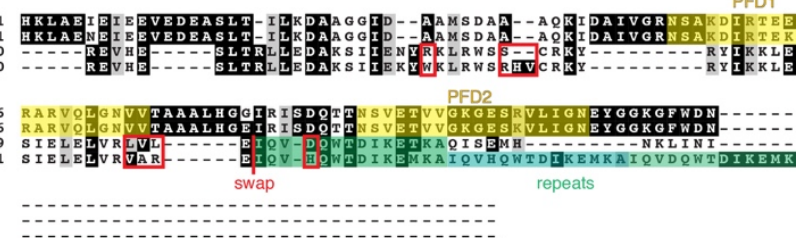

AIOVDOWIDIKEMKAIOVDOWTDIKEMKAOISEKHAK

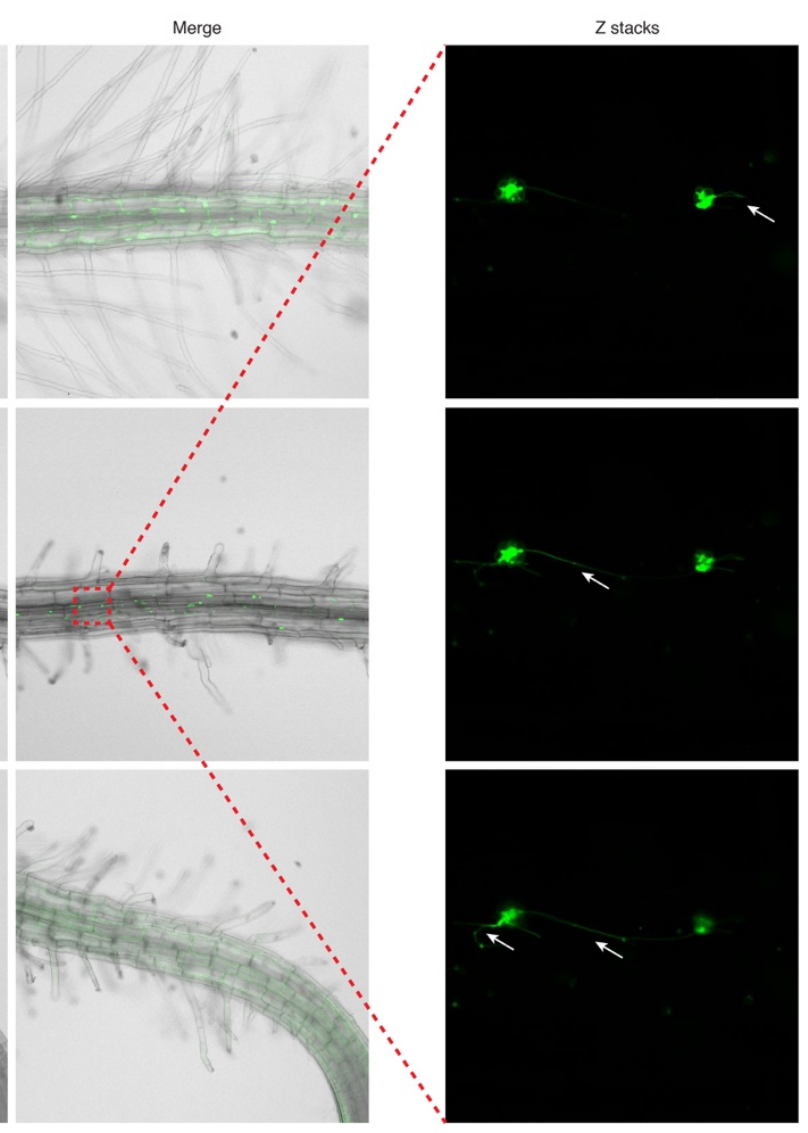

Figure S6. Aggregation of HR4Fei-0 contributes to its cytotoxic activity

(A) Protein accumulation for truncated HR4Fei-0 variants expressed in N. benthamiana; arrow indicates SDSresistant dimers. (B) Protein sequence alignment between fungal Het-s, Het-S, HR4Fei-0 and HR4Col-0, indicating Het-s/Het-S prion-forming domain (PFD, yellow), HR4 repeats (green), and HR4 domain boundary used for HR4Col-0/HR4Fei-0 swaps. (C) Confocal images of transgenic lines expressing inducible GFP-only, HR4Fei-0_GFP, and HR4Col-0_GFP after $10 \mathrm{~h}$ treatment with $\beta$-estradiol. Arrows point to Z-membrane like structures. DIC, Differential Interference Contrast. 